\title{
Investment Performance of Swiss Pension Funds and Investment Foundations
}

\author{
Manuel Ammann and Andreas ZingG*
}

\author{
Keywords: Investments; Performance; Pension funds; Switzerland \\ JEL-Classification: G11, G23
}

\begin{abstract}
We investigate the performance of domestic and international bond and equity portfolios of Swiss pension funds and investment foundations over the period of 1996 to 2006. Our sample consists of 73 pension funds and 13 investment foundations with total assets of more than CHF 200 billion. We find some indications for superior skills of security selection and timing by pension funds in international bond management even net of costs for asset management and fund administration. In contrast, we find a significant net underperformance for domestic bonds, domestic equities and international equities. For investment foundations, we find a significant net underperformance for domestic bonds and international equities, whereas for international bonds and domestic equities the null hypothesis of neither significant out- or underperformance cannot be rejected. Finally, we find no evidence of persistence in the performance of Swiss pension funds and investment foundations.
\end{abstract}

\section{Introduction}

Today, retirement provisions in the western hemisphere - be it private or publicly organized - face the general problem of longer periods of retirement due to a higher average life expectancy but shrinking labor force due to a declining birth-rate ${ }^{1}$. This puts governments and pension funds in a situation of decreasing contributions but increasing expenditures. As a consequence, retirement plans and pension funds, which are based on the funding principle, have to rely more and more on their capital gains and hence on the investment performance achieved on capital markets.

The dependence on the investment performance has also increased in the second pillar of the Swiss retirement provisions system. Moreover, Swiss pension funds have

*University of St. Gallen, Swiss Institute of Banking and Finance, Rosenbergstrasse 52, 9000 St. Gallen. E-mail: manuel.ammann@unisg.ch, andreas.zingg@ubs.com. We would like to thank Ralf Seiz, Alexander Ising, Stephan Süss, Michael Verhofen, Evert Wipplinger, Rico von Wyss, and an anonymous referee for their helpful comments. Watson Watt, the Swiss Pension Fund Association (ASIP), and the Conference of Managers of Investment Foundations (KGAST) are gratefully acknowledged for providing the data.

${ }^{1}$ See Scenarios for Population Development in Switzerland 2005-2050 of the Swiss Federal Statistical Office (EIDGENOSSENSCHAFt, 2006). 
to guarantee high returns on the savings and pensioners' covering capital. Considering administration costs and provisions for longevity and value fluctuation reserves, an average Swiss pension fund requires a long-term investment return between 4 and 5 percent to keep its financial balance ${ }^{2}$. Given the high return guarantees, it is crucial for the stability of the Swiss retirement provision system, that pension funds realize adequate risk-adjusted investment returns.

Although Switzerland has a well developed occupational pension scheme with a long tradition, little research has been done on the investment performance of Swiss pension funds so far. Previous research is limited to the performance of collective investments of Swiss pension funds such as investment foundations (AMmanN, HAELLER AND VON WYSS, 2002). In this article, we investigate the performance of domestic and international bond and equity portfolios of Swiss pension funds over the period of 1996 to 2006. Moreover, we examine the Swiss legal investment regulations and their influence on the investment strategy of pension funds within the analyzed asset classes. Finally, we compare the performance and investment strategies of pension funds with Swiss investment foundations ${ }^{3}$. Our analysis is based on a data sample consisting of 73 pension funds and 13 investment foundations provided by the Swiss Pension Fund Association (ASIP) and the Conference of Managers of Investment Foundations (KGAST) ${ }^{4}$.

The article is structured as follows: In Section 2, we review the previous research on the investment performance of pension funds. Section 3 provides a brief overview of the investment regulations for Swiss pension funds. Section 4 provides a description and initial characterization of our data set and in Section 5 we present the models of performance measurement for equities and bonds. The results of the performance analysis are presented in Section 6 . The persistence of the empirical results is verified in Section 7. Finally, Section 8 concludes.

\section{Literature}

So far, little research has been done on the investment performance of Swiss pension funds. Ammann, Haeller, AND von Wyss (2002) examine the performance of domestic and international equity portfolios of six Swiss investment foundations over the period from January 1995 to September 2002. They find no systematic effect of security selection and partly negative returns from market timing. The authors emphasize that for Swiss investment foundations, on average, the risk-adjusted performance of domestic equities tends to be higher than the performance of international equities.

In contrast to the limited literature on the investment performance of Swiss pension funds, there is broad evidence on the performance of U.K. and U.S. pension

\footnotetext{
${ }^{2}$ Estimate is based on the following assumptions: statutory minimum interest rate of $2.5 \%$ on the savings capital of active contributors, technical interest rate of $3.8 \%$ on the pensioners'covering capital, provisions for longevity and fluctuation reserves of $0.5 \%$ in each case and administration costs of $0.3 \%$.

${ }^{3}$ Investment foundations are tax-exempt institutions for the collective investment (investment foundations are fund-like investment products) of pension funds. Investment foundations are exclusively available to pension funds.

${ }^{4}$ The Swiss Pension Fund Association (ASIP) and the Converence of Managers of Investment Foundations (KGAST) are gratefully acknowledged for providing the data sample.
} 
funds' equity holdings. Beebower And Bergstrom (1977) and Ippolito And TURNer (1987) both find that the average performance of U.S. pension funds' equity holdings lags behind the S\&P 500 on a risk-adjusted basis. Examining 769 U.S. pension funds, Lakonishok, Shleifer, Vishny, Hart, and Perry (1992) find that the equity performance of funds underperforms the S\&P 500 by 1.3 percent per year from 1983 to $1989^{5}$. However, they make no risk adjustment and do not distinguish between security selection and market timing skills.

Coggin, Fabozzi, And Rahman (1993) were the first to investigate the security selection and market timing performance by analyzing a sample of 71 U.S. equity pension fund managers for the period of January 1983 to December 1990. They find that the average contribution of security selection to be positive, the average timing ability to be negative. However, more recent research does not confirm these findings. THOMAS AND TONKS (2001) investigate the performance of the domestic equity portfolios of 2,175 U.K. pension funds over the period from 1983 to 1997. Returns from security selection and market timing are both negative. On average, they find no statistically significant out- or underperformance. Moreover, Timmermann And Blake (2005) and Blake And Timmermann (2005) analyze a panel of 247 U.K. pension funds' foreign equity holdings from 1991 to 1997 and find negative returns both from international market timing and from selecting stocks within individual foreign regions. The average fund underperformed a passive global equity benchmark by 70 basis points per annum on a risk-adjusted basis. Moreover, the authors show that the underperformance in international stocks is substantially greater than in their domestic equity market.

Not surprisingly, research on investment performance of U.S. and U.K. pension funds is focussed on equities because equities account on average for 50 to 70 percent $^{6}$ of pension funds' assets in these two countries. Nevertheless, there are some systematic multiple-asset-class investigations of pension funds ${ }^{7}$. Brinson, Hood, And Beebower (1986) and Brinson, Singer, And Beebower (1991) were the first to examine investment performance of multiple-asset-class pension fund portfolios by analyzing active investment decisions of large U.S. pension plans. They find no statistically significant contribution of security selection and market timing. Overall, they find no statistically significant out- or underperformance of pension funds relative to their policy benchmarks. Examining the asset allocation of 306 U.K. pension funds from 1986 to 1994, Blake, Lehmann, and Timmermann (1999) find even negative average returns from market timing across asset classes $^{8}$.

Summarizing, previous research on the investment performance of pension funds provides little evidence for superior performance of pension funds relative to passive benchmarks. In fact, the contribution of active management seems to be even negative. Finally, the risk-adjusted performance of domestic asset classes tends to be

\footnotetext{
${ }^{5}$ Equally-weighted performance before management fees of the equity portion of the funds (cash excluded) in comparison to the S\&P 500 Total Return Index from 1983 to 1989.

${ }^{6}$ For U.S. pension funds' average effective asset allocation see Brinson, Singer, ANd BeEBower (1991), for U.K. pension funds' average effective asset allocation see THOMAS AND TONKS (2001).

${ }^{7}$ In a multiple-asset-class performance analysis, market timing is the contribution from variations in the allocation of funds across asset classes. Security selection is the contribution from allocation of funds within asset classes.

${ }^{8}$ The analyzed asset classes are domestic and international equities, domestic and international bonds, index-linked bonds, cash as well as domestic and international property.
} 
higher than the performance of international asset classes.

\section{Investment regulations for pension funds in Switzer- land}

The Swiss Federal Law on Occupational Old-age, Survivors' and Disability Pension Plan (LPP) contains regulations to which Swiss pension funds must comply for their investments. Pension fund assets have to be managed prudently to ensure the safety of assets, achieve a reasonable return on investments, maintain a suitable diversification of risks, and allow for the liquidity requirements of the plan $^{9}$. In addition, Swiss pension funds face quantitative limitations on their investments in equities, bonds, mortgages and real estate. The currently imposed limits include an overall limit on equities of 50 percent including domestic and international equities. Furthermore, there are sub-limits on domestic equities (30 percent) and international equities ( 25 percent). The limits on bonds include a 20 percent constraint on foreign currency bonds and a 30 percent constraint on foreign CHF bonds. In addition, there is a limit on domestic real estate of 50 percent and 75 percent on mortgages respectively. Additional limits are placed on combinations of asset classes. The total share of foreign currency investments may not exceed 30 percent. Finally, there is a combined limit of 70 percent on equities and real estate.

Since 2000 the quantitative limitations can be exceeded if the pension fund can justify them as part of a prudent investment policy ${ }^{10}$. According to recent surveys ${ }^{11}$, almost 80 percent of the Swiss pension funds make use of the prudent investor rule and exemptions from the quantitative limitations thus have become the rule. Furthermore, quantitative limitations influence, in particular, the strategic asset allocation of pension funds, but are less important for the investment strategy within the individual asset classes, which is the focus of this article. In contrast, the safety principle as well as the liquidity requirements mentioned above are likely to influence the investment strategy within asset classes since pension funds consider both principles when they define their internal investment regulations.

Internal investment regulations of Swiss pension funds often contain certain minimum credit ratings for bonds. For example, the Swiss Federal Pension Fund "Publica" requires a credit rating of at least A3 (Moody's) for domestic and international bonds. Furthermore, bond investments are often restraint to certain minimum issue volumes to satisfy the liquidity requirements. As a result, we expect the bond portfolios of pension funds to have a tilt towards government bonds since these bonds tend to have higher ratings and larger issue volumes.

Equally important for stocks and bonds are self-restraints of the investment horizon. Admissible investments are often limited to the constituents of the respective benchmark index. For example, domestic equity investments of the Swisscom pension fund "comPlan" are restricted to SMI and SPI constituents. Since the se-

\footnotetext{
${ }^{9}$ Article 71 of the Swiss Federal Law on Occupational Old-age, Survivors' and Disability Pension Plan. In addition, Articles 49-60 of the Ordinance on the Occupational Old-Age, Survivors' and Disability Benefit Plans (OOB2).

${ }^{10}$ Article 59 of the Ordinance on the Occupational Old-Age, Survivors' and Disability Benefit Plans (OOB2).

${ }^{11}$ Compare 8th edition of the Swiss Institutional Survey (Lusenti, 2007).
} 
lection criteria of the commonly used benchmark indices often contain minimum requirements concerning credit quality, issue trade volumes, we expect a tilt of bond portfolios towards government bonds and of equity portfolios towards large caps.

Summarizing, investment regulations for Swiss pension funds are not expected to have a direct effect on the investment strategies within the individual asset classes. However, we expect the statutory investment regulations to have an indirect effect, since many pension funds seem to constrain themselves more than required by regulation. We hypothesize that these self-constraints affect investment strategies in favor of government bonds and large caps.

\section{Data}

Watson Wyatt ${ }^{12}$ and the Swiss Pension Fund Association (ASIP) provided an anonymized sample of monthly performance data from 73 Swiss pension funds over the period from January 1996 to June 2006. The data are from the so-called "ASIP Performance Comparison", a comparison of Swiss pension funds' investment performance that Watson Wyatt conducts on behalf of the Swiss Pension Fund Association twice per year.

Table 1: Size of the pension fund data sample

Number of pension funds in the data sample from 1996 to 2006. The size of the sample is measured always at the beginning of each year.

\begin{tabular}{ccccccc}
\cline { 2 - 3 } \cline { 5 - 6 } \cline { 5 - 6 } & \multicolumn{2}{c}{ Bonds } & & \multicolumn{2}{c}{ Equities } \\
\hline 1996 & Domestic & International & & Domestic & International \\
1997 & 7 & 2 & & 4 & 2 \\
1998 & 14 & 3 & & 6 & 4 \\
1999 & 22 & 8 & & 12 & 11 \\
2000 & 29 & 22 & & 33 & 27 \\
2001 & 36 & 27 & & 38 & 32 \\
2002 & 44 & 37 & & 47 & 41 \\
2003 & 48 & 41 & & 49 & 46 \\
2004 & 49 & 43 & & 50 & 47 \\
2005 & 48 & 42 & & 49 & 46 \\
2006 & 47 & 41 & & 47 & 45 \\
\hline
\end{tabular}

In general, there are monthly performance data on domestic and international bond and equity holdings for each pension fund. However, the data sample is not complete for all of the 73 pension funds. The majority of pension funds has joined the performance comparison later than 1996. Thus, performance data is not available for all pension funds from January 1996 to June 2006. Moreover, some pension funds do not report performance data for all asset classes separately, but only for selected asset classes or even only for total assets. International bond and equity

${ }^{12}$ Watson Wyatt is one of the largest consultants to institutional investors. 
portfolios that are not globally diversified across multiple regions or currencies, such as Equities North America, Equities Emerging Markets or Bonds Euro, are excluded from the analysis. Table 1 reports the size of the data sample per asset class for the years 1996 to 2006 .

Table 2: Size of the investment foundation data sample

Number of investment foundations in the data sample from 1996 to 2006. The size of the sample is measured at the beginning of each year.

\begin{tabular}{ccccccc}
\cline { 2 - 3 } \cline { 5 - 6 } \cline { 5 - 6 } & \multicolumn{2}{c}{ Bonds } & & \multicolumn{2}{c}{ Equities } \\
\hline 1996 & 5 & 6 & & 6 & \\
1997 & 5 & 7 & & 7 & 8 \\
1998 & 6 & 7 & & 10 & 8 \\
1999 & 7 & 8 & & 10 & 8 \\
2000 & 9 & 8 & & 11 & 8 \\
2001 & 9 & 8 & & 11 & 8 \\
2002 & 11 & 10 & & 12 & 9 \\
2003 & 11 & 10 & & 12 & 10 \\
2004 & 12 & 11 & & 13 & 12 \\
2005 & 13 & 11 & & 13 & 12 \\
2006 & 13 & 11 & & 13 & 12 \\
\hline
\end{tabular}

The data is free of survivorship bias since it includes also time series of pension funds that stopped participating in the performance comparison ${ }^{13}$. Our sample can be considered representative with respect to pension capital coverage. With assets of about CHF 150 billion as of June 2006, the 73 pension funds in our sample account for about 20 to 25 percent of assets of all Swiss pension funds. In contrast, our sample is not representative with respect to size distribution. With an average pension fund size of almost CHF 2 billion, the data is biased towards larger pension funds. As a result, we might overestimate the risk-adjusted performance of pension funds, since previous research uncovered a positive association between pension fund performance and fund size (Ambachtsheer, Capelle and Scheibelhut, 1998).

The Conference of Managers of Investment Foundations (KGAST) and Watson Wyatt provided monthly performance data on 13 Swiss investment foundations over the period from January 1996 to June 2006. As of 2006, the 13 investment foundations have assets of more than CHF 60 billion. The data is from the so-called "KGAST Performance Comparison", which is conducted by Watson Wyatt on behalf of the Conference of Managers of Investment Foundations on a quarterly basis. For each investment foundation we have performance data on domestic and international equity and bond portfolios. The asset managers of the investment foundations in our sample are Asset Allocation Access (AAA), Allianz, Winterthur Insurance Company (AWI), Baloise, Credit Suisse (CSA), IST, Lombard Odier Darier Hentsch $(\mathrm{LODH})^{14}$, Patria, Sarasin, Swiss Life, Swisscanto, UBS and Zurich Insurance Com-

\footnotetext{
${ }^{13} 2$ of the 73 pension funds stopped participating in the performance comparison.

${ }^{14}$ The investment foundation of Lombard Odier Darier Hentsch was acquired by IST as of De-
} 
pany.

As shown in Table 2, performance data is not available for all investment foundations over the entire period of investigation. Some investment foundations have not participated in the performance comparison from the beginning or were founded after January 1996. Moreover, some asset managers do not offer international bonds or equities with a global investment universe, i.e., the offering does not contain products that are diversified across multiple regions or currencies. For example, LODH's product offering does not contain international bonds, whereas Zurich offers international bond and equity products only for selected currencies (USD, EUR) and regions (Europe, U.S., Japan, Emerging Markets). The investment foundation performance data is free of survivorship bias since no investment foundation stopped participating in the performance comparison. Finally, our sample seems to be representative since it covers all large investment foundations in Switzerland ${ }^{15}$.

Table 3: Estimated average asset management and administration costs of investment foundations

Average costs of investment foundations in basis points of the net asset value based on the annual reports of years 2004 and 2005. Costs include management fees, administration costs, taxes and interest payable. The net asset value is the average of the net asset value at the beginning and at the end of the year.

\begin{tabular}{lcccccc}
\cline { 2 - 3 } \cline { 5 - 6 } \cline { 5 - 6 } \cline { 5 - 6 } & \multicolumn{2}{c}{ Bonds } & & \multicolumn{2}{c}{ Equities } \\
\cline { 2 - 3 } \cline { 5 - 6 } AAA & Domestic & International & & Domestic & International \\
Allianz & 35 & 57 & & & 113 & 7 \\
AWI & 17 & 41 & & 31 & 78 \\
Baloise & 41 & 68 & & 71 & 95 \\
CSA & 16 & 27 & & 33 & 80 \\
IST & 21 & 54 & & 60 & 92 \\
LODH & 44 & - & & 70 & 74 \\
Patria & 46 & 44 & & 48 & 83 \\
Sarasin & 50 & 53 & & 71 & 87 \\
Swiss Life & 27 & 47 & & 64 & 82 \\
Swisscanto & 26 & 17 & & 29 & 24 \\
UBS & 31 & 50 & & 65 & 112 \\
Zurich & 34 & - & & 73 & - \\
\hline Average & 32 & 46 & & 61 & 75 \\
\hline
\end{tabular}

Investment performance of pension funds is calculated by Watson Wyatt in gross terms before deduction of any management fee and fund administration costs but net of all direct trading costs and embedded fees. In contrast, the performance of investment foundations is based on the net asset value and is therefore calculated net of all costs. To ensure comparability, we estimate costs of asset management

cember 2006 .

${ }^{15}$ Our data sample does not contain investment foundations only invested in real estate, such as Pensimo, Turidomus or Testina. 
and fund administration for investment foundations based on their 2004 and 2005 annual reports. Our cost estimate $C_{t, i}$ for the investment foundation i includes management fees $(M A N)$, fund administration costs $(A D M I N)$, taxes $(T A X)$ and interest payable $(I N T)$ :

$$
C_{t, i}=\frac{M A N_{i, t}+A D M I N_{i, t}+T A X_{i, t}+I N T_{i, t}}{\frac{1}{2}\left(N A V_{\text {Start }, i, t}+N A V_{E n d, i, t}\right)},
$$

where $N A V_{\text {Start }, i, t}$ is investment foundation i's net asset value at the beginning and $N A V_{E n d, i, t}$ is its net asset value at the end of the year t. Thus, estimated costs of investment foundations for asset management and fund administration are related to the average net asset value. Finally, we calculate the gross performance of investment foundations by adding the arithmetic average of the costs estimated for the years 2004 and 2005 to the annual net performance.

Table 4: Returns and volatilities of pension funds and investment foundations in the sample

Annualized average of the cross-sectional average of gross returns (Panel A) and the crosssectional average of volatilities (Panel B) of pension funds, investment foundations and respective benchmark indices from January 1996 to June 2006. The benchmark indices are the Swiss Bond Index for domestic bonds, the Lehman Global Aggregate Bond Index for international bonds, the Swiss Performance Index for domestic equities and the MSCI World Index for international equities.

\begin{tabular}{|c|c|c|c|c|}
\hline & Pension funds & Investment foundations & Index \\
\hline \multicolumn{5}{|c|}{ Panel A: Gross returns } \\
\hline \multirow{2}{*}{ Bonds } & Domestic & $3.34 \%$ & $3.81 \%$ & $3.69 \%$ \\
\hline & International & $5.79 \%$ & $5.68 \%$ & $5.77 \%$ \\
\hline \multirow[t]{2}{*}{ Equities } & Domestic & $9.33 \%$ & $9.86 \%$ & $9.82 \%$ \\
\hline & International & $6.79 \%$ & $7.24 \%$ & $8.05 \%$ \\
\hline \multicolumn{5}{|c|}{ Panel B: Volatilities } \\
\hline \multirow[t]{2}{*}{ Bonds } & Domestic & $2.35 \%$ & $2.73 \%$ & $2.60 \%$ \\
\hline & International & $5.05 \%$ & $5.71 \%$ & $7.05 \%$ \\
\hline \multirow[t]{2}{*}{ Equities } & Domestic & $15.35 \%$ & $16.59 \%$ & $17.15 \%$ \\
\hline & International & $17.46 \%$ & $16.75 \%$ & $18.55 \%$ \\
\hline
\end{tabular}

As mentioned, investment performance of pension funds is provided in gross terms. However, only the net performance allows a fair assessment of active and passive management. Therefore, we additionally estimate the net performance of pension funds. Because the sample is anonymized, we use costs of investment foundations to estimate net performance of pension funds. Summarizing, gross performance of pension funds and net performance of investment foundations are the original performance data, net performance of pension funds and gross performance of investment foundations are estimates calculated to make the performance of pension funds and investment foundations comparable. 
Table 3 shows the estimated costs of investment foundations for asset management and fund administration. Estimated costs for AAA's domestic and international equities deviate extremely from the average. While for AAA's domestic equities estimated costs are far above average, costs for AAA's international equities are heavily below average. The allocation of costs between domestic and international equities might potentially be biased. Therefore, we exclude AAA's domestic and international equities from the performance analysis.

A first impression of our data sample is provided in Table 4. It shows the annualized average of the cross-sectional average of returns and the cross-sectional average of volatilities of pension funds, investment foundations, and of the respective benchmark indices. The set of benchmark indices includes the Swiss Bond Index (SBI), the Lehman Global Aggregate Bond Index, the Swiss Performance Index (SPI) and the MSCI World Index. All of the benchmark indices are total return indices. These benchmark indices have the virtue of being independently calculated indices that are immediately publicly available and widely used for performance measurement in Switzerland.

\section{Models of performance measurement}

A fair assessment of the investment performance requires an asset pricing model to estimate risk-adjusted benchmark returns. This section briefly describes the models used for the risk adjustment.

\subsection{Performance measurement of bonds}

Alternative asset pricing models for bonds are the Capital Asset Pricing Model (CAPM), the three-factor model of FAMA AND FRENCH (1993) involving a default and a term factor as well as the multi-index models proposed by BLAKE, ELTON, and Gruber (1993). Furthermore, Elton, Gruber, and Blake (1995) proposed a six-factor model including a bond and a stock market index, a factor representing default risk, a measure of the returns on mortgage securities as well as two factors that incorporate unexpected changes in macro-economic measures of inflation and GNP growth. Our performance analysis of bonds is based on the model of Elton, Gruber, and Blake (1995). In contrast to the original model, we omit both expectational macro-economic variables and the returns on mortgage securities. These variables are difficult to construct as "global" factors explaining the returns of global bond portfolios. Thus, our performance measurement model for domestic and international bonds includes a bond and a stock market index as well as two factors representing term and default risk:

$$
R_{i, t}-R_{f, t}=\alpha_{i}+\beta_{i} R B M R F_{t}+s_{i} R S M R F_{t}+t_{i} T E R M_{t}+d_{i} D E F T_{t}+\varepsilon_{i, t} .
$$

$R_{i}-R_{f}$ represents the monthly returns of pension fund or investment foundation $\mathrm{i}$ in excess of the 1-month CHF LIBOR. For domestic bonds, $R B M R F$ is the excess return of the Swiss Bond Index (SBI), for international bonds it is the excess return of the Lehman Global Aggregate Bond Index. RSMRF is the excess return of the Swiss Performance Index (domestic bonds) and of the MSCI World Index (international bonds), respectively. TERM is a zero investment, factor-mimicking 
portfolio representing the risk of unexpected changes in interest rates. For domestic bonds, it is the return of the Citigroup World Government Bond Index Switzerland $10 \mathrm{Y}+{ }^{16}$ minus the return of the Citigroup World Government Bond Index Switzerland $1-3 \mathrm{Y}^{17}$. For international bonds, it is the difference between the return on the Citigroup World Government Bond Index 10Y+ and the return on the Citigroup World Government Bond Index 1-3Y. Thus, TERM represents the average return difference between long-term and short-term government bond portfolios. DEFT represents a zero investment portfolio mimicking the default factor. It is defined for domestic bonds as the average of the returns on the SBI Domestic Non-Government and the SBI Foreign Corporate minus the average of the returns on the SBI Domestic Government and the SBI Foreign Government. For international bonds it is the return on the Lehman Global Corporate Index minus the return on the Lehman Global Treasury Index. Thus, DEFT is the average return difference between corporate and government bond portfolios. Finally, the intercept $\alpha_{i}$ is a measure of pension fund or investment foundation i's performance relative to the four-factor benchmark. A positive intercept suggests a superior performance, and a negative intercept suggests an underperformance relative to the four-factor benchmark on a risk-adjusted basis.

\section{Table 5: Correlations of bond factor portfolios}

Correlations of the variables explaining the returns of domestic (Panel A) and international bonds (Panel B). Panel A is based on the reference period of 1996 to 2006, Panel B is based on the reference period of 2001 to 2006. RBMRF is the excess return of the bond market, RSMRF the excess return of the stock market. TERM and DEFT are factor-mimicking portfolios representing the term and the default risk.

\begin{tabular}{|c|c|c|c|}
\hline & RBMRF & RSMRF & TERM \\
\hline \multicolumn{4}{|c|}{ Panel A: Domestic bonds } \\
\hline RSMRF & -0.16 & & \\
\hline TERM & 0.84 & -0.07 & \\
\hline DEFT & -0.68 & 0.17 & -0.82 \\
\hline \multicolumn{4}{|c|}{ Panel B: International bonds } \\
\hline RSMRF & 0.45 & & \\
\hline TERM & 0.29 & -0.32 & \\
\hline DEFT & 0.57 & 0.47 & 0.03 \\
\hline
\end{tabular}

The bond factor correlations are reported in Table 5. In order to cope with the problem of multicollinearity, factors with correlations above 0.5 are orthogonalized before being used as regressors. Note that the reference period for international bonds is from January 2001 to June 2006, whereas the reference period for domestic bonds is from 1996 to 2006 . We had to shorten the reference period for international bonds because historical data on the required global bond indices is not available until the year 2001. Finally, the performance measurement model is estimated with

\footnotetext{
${ }^{16}$ The index consists of Swiss government bonds with maturities of 10 and more years.

${ }^{17}$ The index consists of Swiss government bonds with maturities of 1 to 3 years.
} 
panel-corrected standard errors (PCSE) according to BECK AND KATZ $(1995)^{18}$.

For international bonds, we employ an additional model of performance measurement. To capture potential currency effects, we follow DeTzLER (1999) and expand the benchmark model by exchange rate factors. Because USD, EUR and JPY account for almost 90\% of the Lehman Global Aggregate Bond Index, we include these three currencies in our model. The factor loadings on the currency returns could give some indications of the currency allocation. All currency returns are orthogonalized before being used as regressors.

\subsection{Performance measurement of equities}

Potential models of performance measurement for equities are the single-factor Capital Asset Pricing Model (CAPM), the three-factor model described by FAMA AND French (1993) and the four-factor model of CARHART (1997). We employ Fama and French's three-factor model for our performance analysis ${ }^{19}$ :

$$
R_{i, t}-R_{f, t}=\alpha_{i}+\beta_{i} R S M R F_{t}+s_{i} S M B_{t}+h_{i} H M L_{t}+\varepsilon_{i, t},
$$

where $R_{i}-R_{f}$ represents the monthly returns of pension fund or investment foundation i in excess of the 1-month CHF LIBOR. $R S M R F$ represents the return of the Swiss Performance Index (domestic equities) and the MSCI World Index (international equities), respectively, in excess of the 1-month CHF LIBOR. $S M B$ and $H M L$ are returns on zero-investment, factor-mimicking portfolios for size and bookto-market equity. Finally, the intercept $\alpha_{i}$ is a measure of pension fund or investment foundation i's risk-adjusted performance relative to the three-factor benchmark.

We use the S\&P/Citigroup Broad Market Index (BMI) to construct the factormimicking portfolios for domestic and international equities ${ }^{20}$. The BMI is divisible into two sub-indices, the Primary Market Index (PMI), which represents the top $80 \%$ of market capitalization in each country, and the Extended Market Index (EMI), which represents the bottom $20 \%$ of the market capitalization in each country. Both the PMI and the EMI are further divided into a growth and a value style index. Thus, four BMI sub-indices result: PMI Growth, PMI Value, EMI Growth and EMI Value. The size-factor-mimicking portfolio $S M B$ (small minus big) is the difference between the average of the returns on the two small cap indices, EMI Growth and EMI Value, and the average of the returns on the two large cap indices, PMI Growth and PMI Value. Thus, $S M B$ is the difference between the returns on small and big stock portfolios with about the same weighted-average book-to-market equity. Therefore, this difference should be largely free of the value factor in returns. Finally, $H M L$ (high minus low), mimicking the book-to-market equity factor, is the difference between the average of the returns on the two value indices, PMI Value and EMI Value, and the average of the returns on the two growth indices, PMI Growth and EMI Growth. The two components of $H M L$ are returns with about

\footnotetext{
${ }^{18}$ According to Beck and Katz (1995) the PCSE specifications adjust for the contemporaneous correlation and heteroscedasticity among returns as well as for autocorrelation within each pension funds' and investment foundation's returns.

${ }^{19}$ Momentum factor for the Swiss stock market of Ammann and Steiner (2008) was not yet available at the time of the analysis.

${ }^{20}$ We use the Global Broad Market Index including 27 countries for international equities and the Broad Market Index Switzerland for domestic equities.
} 
the same weighted-average size so that the returns of $H M L$ should be largely free of the size factor in returns. The correlations of the factor portfolios are displayed in Table 6. Because of the low correlations, none of the factors is orthogonalized before being used as regressors. We estimate the performance measurement model with panel-corrected standard errors (PCSE).

Table 6: Correlations of equity factor portfolios

Correlations of the variables explaining the returns of domestic (Panel A) and international equities (Panel B). Panel A and B are based on the reference period 1996 to 2006. RSMRF is the excess return of the stock market. SMB and HML are factor-mimicking portfolios for size and book-to-market equity.

\begin{tabular}{lcc}
\cline { 2 - 2 } & RSMRF & \multicolumn{1}{c}{ SMB } \\
\hline Panel A: & Domestic equities \\
\hline SMB & 0.06 & \\
HML & 0.42 & -0.02 \\
\hline Panel B: & International equities \\
\hline SMB & -0.15 & \\
HML & -0.47 & -0.10 \\
\hline
\end{tabular}

For international equities, we employ an additional model of performance measurement to capture potential currency effects. For this purpose, we draw on the model of Cumby and GLen (1990). Instead of using a trade-weighted currency index, we expand the three-factor model of Fama and French by exchange rate factors. Because each of the currencies USD, EUR, JPY, and GBP represent between $10 \%$ and $50 \%$, and all four currencies in total about $90 \%$ of the MSCI World Index, we incorporate these four currencies in our model. The loadings on the currency factors can reveal some information on the currency allocation. All currency returns are orthogonalized before being used as regressors.

\subsection{Limitations of performance measurement models}

Performance measurement models have certain limitations that can affect the interpretation of the empirical results. First, empirical results might be biased due to omitted variables. A low adjusted $\mathrm{R}^{2}$ is an indicator for omitted variables. As shown in Section 6, the explanation content of the applied asset pricing models is comparatively high. Therefore, the missing factor bias in our empirical results is expected to be rather small. Since we do not expect pension funds and investment foundations to have negative exposures to potential missing systematic risk factors, the alphas tend to be overestimated in case of missing variables. Thus, the missing variable bias seems to be relevant, in particular, in case of an outperformance.

A second limitation are potential measurement errors in the variables. The indices used for the factor portfolios have weightings that can differ substantially from those of pension funds and investment foundations in the sample. This issue is relevant, in particular, for international bonds and equities. Unfortunately, we have no information on the applied benchmark indices and on the effective asset 
allocation of the pension funds and investment foundations in the sample. To cope with potential measurement errors, at least to a certain extent, we include exchange rate factors in the performance measurement models for international assets. A frequent source of measurement errors are the variables representing the market risk of equities and bonds if the applied benchmark index does not reflect the effective investment strategy. However, the benchmark indices we apply for domestic bonds, domestic equities, and international equities are the standard indices used widely by pension funds and investment foundations. In contrast, for international bonds there is no such standard index. To address this issue, we apply additional benchmark indices for international bonds and compare the results.

Time-varying factor exposures might also lead to biased results of the performance analysis. Fundamental variations in the investment strategy, such as a shift from a value to a growth style, lead to such time-varying factor exposures. To better understand whether this issue materializes in our sample we verify the persistence of the investment strategy in Section 7 by splitting the period of investigation into sub-periods. The comparison of factor loadings reveals information on potential variations in the investment strategy.

Finally, the use of derivatives by pension funds and investment foundations in the sample might lead to non-normally distributed returns and therefore biased results. However, the statutory investment regulations strictly limit the use of derivatives. In fact, pension funds and investment foundations use derivatives mainly to hedge against currency risks. We try to address this issue, at least to a certain extent, by expanding our international performance measurement models by exchange rate factors.

\section{Empirical results}

In this section we present the results of the performance analysis for pension funds' and investment foundations' domestic and international bond and stock holdings.

\subsection{Domestic bonds}

Table 7 reports the results of the panel regression for domestic bonds based on the four-factor model described in the previous section. From 1996 to 2006, the sample includes a total of 3,941 monthly returns of pension funds and 1,177 monthly returns of investment foundations. The positive, but statistically not significant intercepts in Panel A of Table 7 indicate no systematic superior performance of pension funds and investment foundations before costs. However, when looking at individual pension funds and investment foundations, there are outperformers in the sample: $10.20 \%$ of pension funds and $7.69 \%$ of investment foundations significantly outperform the benchmark. On the other hand, $20.41 \%$ of pension funds and $7.69 \%$ of investment foundations show a significant underperformance relative to the benchmark. Furthermore, for investment foundations, we find a significant annual average underperformance of $-0.264 \%$ net of costs for asset management and fund administration as shown in Panel B. If pension funds' costs for asset management 


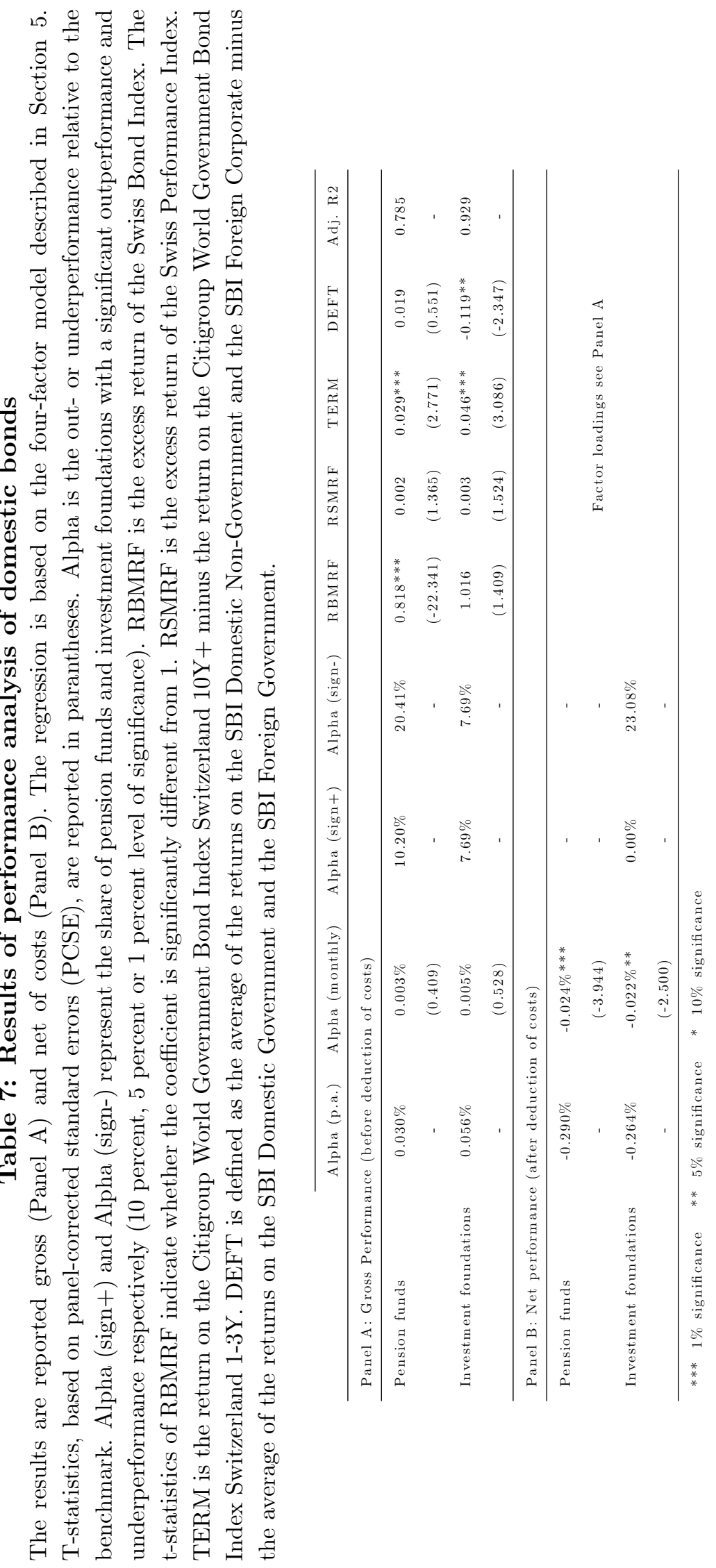


and fund administration are assumed to be of comparable magnitude ${ }^{21}$, an underperformance of $-0.290 \%$ is estimated for pension funds that is significant at the $1 \%$ level. Thus, the null hypothesis of neither significant out- or underperformance is rejected both for pension funds and investment foundations.

The results in Table 7 allow for an assessment of the active and passive nature of bond portfolio management given our benchmark model. As the $R B M R F$ coefficients indicate, pension funds exhibit significantly less bond market risk than investment foundations. While for pension funds the loading on $R B M R F$ is smaller than 1 at a $1 \%$ level of significance, the coefficient for investment foundations is not significantly different from 1 . This is a first indication that investment foundations have remained rather close to the Swiss Bond Index in the period of investigation. This argument is supported when comparing the adjusted $R^{2}$ of the regressions for pension funds and investment foundations. For pension funds, the regression analysis shows an adjusted $R^{2}$ of 0.785 , for investment foundations 0.929 . Consequently, pension funds seem to have followed a relatively active investment approach for domestic bonds. In contrast, investment foundations seem to have followed a more passive investment strategy if measured by our four-factor benchmark. This is a rather surprising result because only 1 out of 13 investment foundations in our sample follows a passive investment strategy according to the official product descriptions.

Finally, the performance measurement model can be interpreted as performance attribution model, where the coefficients on the factor-mimicking portfolios TERM and DEFT reveal information about two elementary investment decisions of bond portfolio management: long-term versus short-term maturities and corporate versus government bonds. The positive loadings on TERM, significant at the $1 \%$ level, indicate that both pension funds and investment foundations have on average a tilt towards long-term maturities. Similarly, the significantly negative loading on $D E F T$ reveals an average tendency of investment foundations towards government bonds across the entire period of investigation. Surprisingly, for pension funds, we find no such government bond tilt. Thus, the effect of the statutory investment regulations is not as expected for pension funds.

Given the high explanatory power of the applied model and the fact that we find a significant underperformance both for pension funds and investment foundations, the missing variable bias should be of minor importance for domestic bonds. The issue of time-varying factor exposures is addressed in Section 7.2.

\subsection{International bonds}

The performance analysis of international bonds is based on a shortened reference period from January 2001 to June 2006 because historical data on some global bond indices used to construct the factor portfolios is not available until the year 2001 . As a result, the sample for international bonds includes 2,565 monthly returns of pension funds and 691 monthly returns of investment foundations.

Table 8 reports the results of the performance analysis based on the four-factor benchmark without exchange rate factors. As indicated by Panel A, we find a significant annual average (gross) outperformance of $1.247 \%$ for pension funds and $0.737 \%$

\footnotetext{
${ }^{21}$ Based on the estimate described in Section 4, average annual costs of asset management and fund administration are assumed to be 32 basis points.
} 


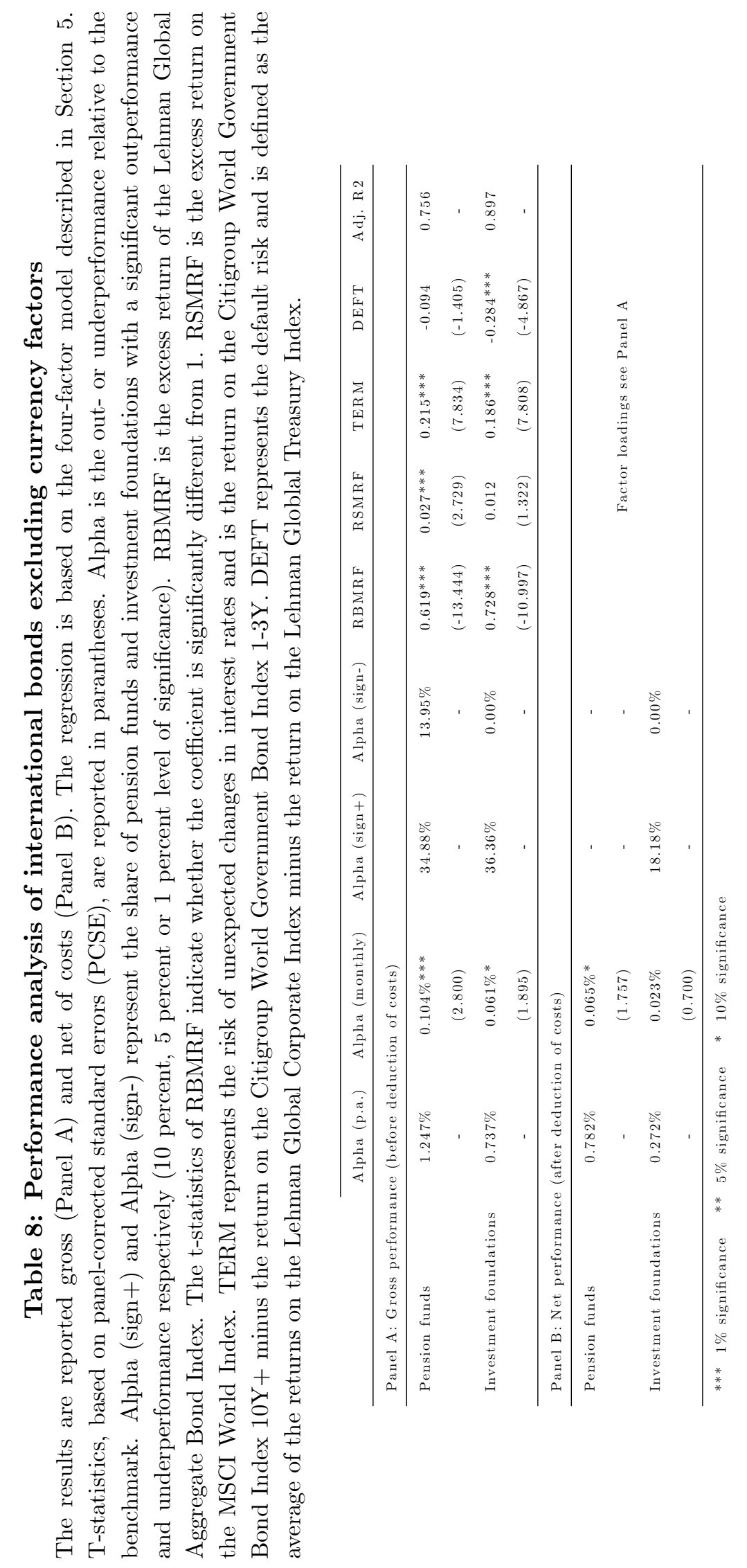




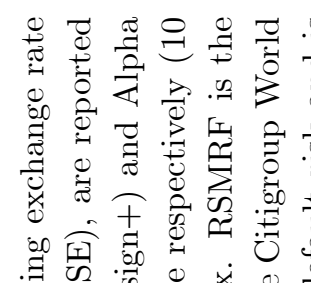

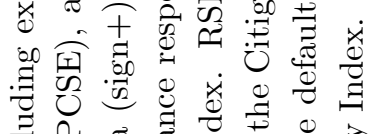

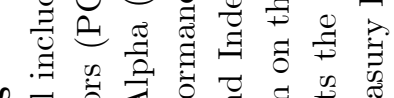

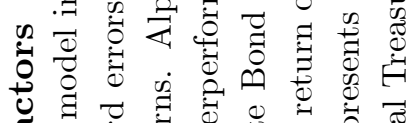

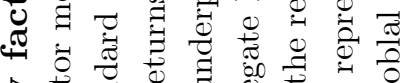

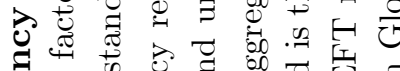

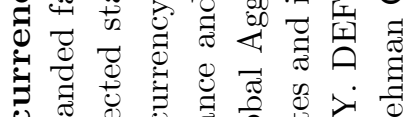

J

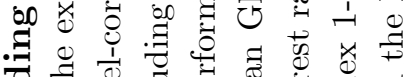

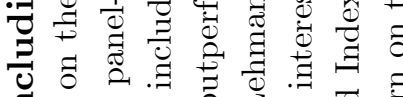

厄)

焉

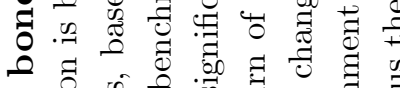

హే

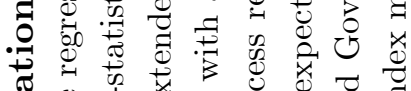

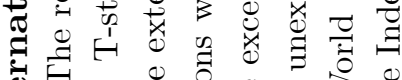

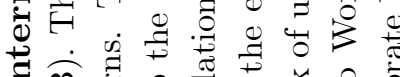

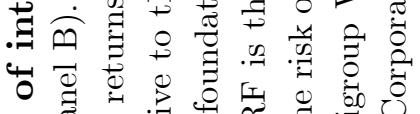

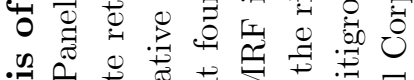

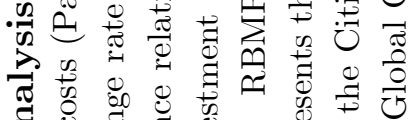

శే

ช

ฮี व

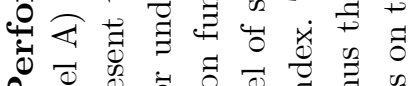

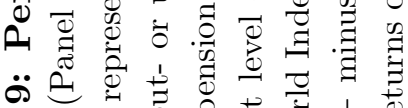

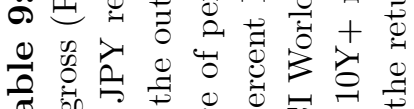

E

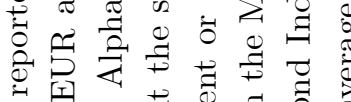
0

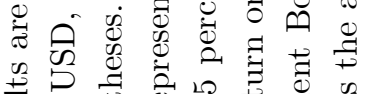

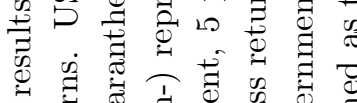

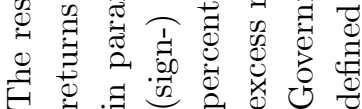

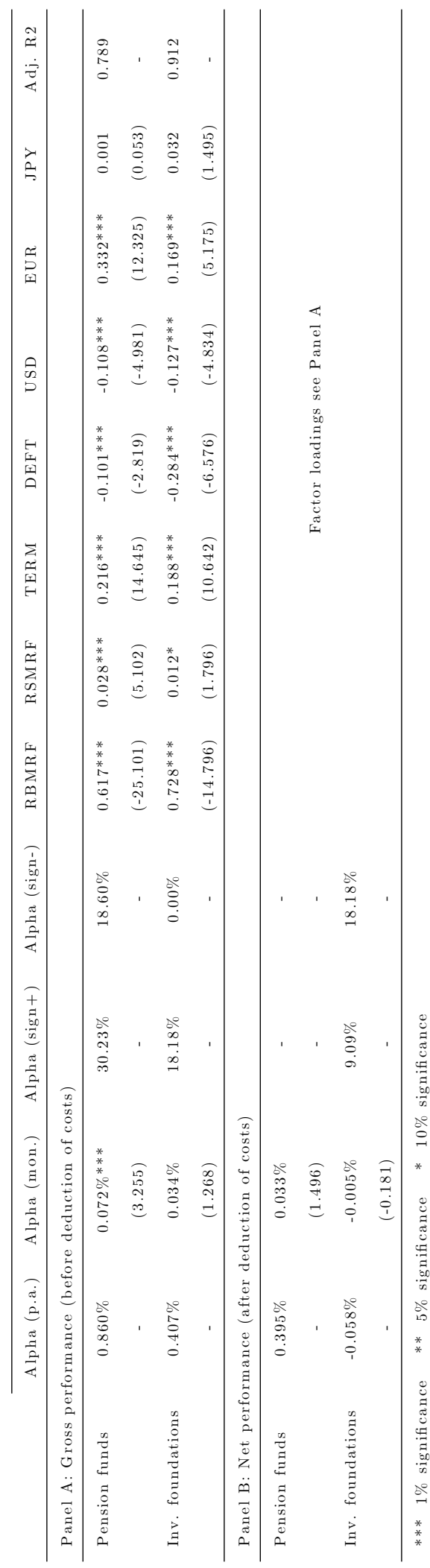


for investment foundations. As shown in Panel B, the outperformance of pension funds remains significant even if costs of asset management and fund administration are considered ${ }^{22}$. In contrast, for investment foundations, we find no significant outor underperformance net of costs.

As indicated by the $R B M R F$ coefficients in Table 8, both pension funds and investment foundations exhibit significantly less bond market risk than the Lehman Global Aggregate Bond Index. In combination with an adjusted $R^{2}$ of 0.756 for pension funds and 0.897 for investment foundations, it can be concluded that in particular pension funds follow a rather active investment approach for international bonds given our benchmark model.

The interpretation of the factor model as performance attribution model enables us to draw some conclusions on the investment style. It seems that both pension funds and investment foundations follow the same investment style for international bonds as for domestic bonds. The positive loadings on TERM, significant at the $1 \%$ level, indicate a tilt towards long-term maturities of pension funds and investment foundations. Concerning the decision corporate versus government bonds, we find a tendency towards government bonds for investment foundations indicated by the negative loading on DEFT significant at the $1 \%$ level. In contrast, for pension funds, we find no statistically significant loading on DEFT and therefore no tendency towards corporate or government bonds.

It must be pointed out that the indices used for the factor portfolios have country and currency weightings that can differ substantially from those of pension funds and investment foundations in the sample (measurement error). For example, the Lehman Global Aggregate Bond Index consists of about 38\% USD, 33\% EUR, and $17 \%$ JPY as of mid-year 2006. Although we have no information on the exact currency allocation, pension funds and investment foundations are likely to hold more EUR at the expense of the USD compared to the Lehman Global Aggregate Bond Index. In order to cope with strongly differing country and currency allocations, we extend the four-factor model by the currency returns on the USD, the EUR, and the $\mathrm{JPY}^{23}$. Significant loadings on the exchange rate factors can indicate over- or underweighting of specific currencies relative to the four-factor benchmark. However, it must be pointed out that significant currency factor loadings could also be due to omitted variables that are highly correlated with the currency returns.

The results of the panel regression for international bonds based on the extended benchmark model are reported in Table 9. As shown in Panel A, the intercepts are smaller but still positive. However, only the outperformance of pension funds remains significant before deduction of costs for asset management and fund administration. If costs are considered, we find no superior performance of pension funds and investment foundations as shown in Panel B. Therefore, the null hypothesis of neither out- or underperformance cannot be rejected.

The currency factors in the extended benchmark model allow for additional conclusions. The highly significant loadings on $U S D$ and $E U R$ are likely to indicate an over- or underweighting of these currencies relative to the four-factor benchmark. Especially an overweighting of the EUR relative to the Lehman Global Aggregate

\footnotetext{
${ }^{22}$ Based on the estimate for investment foundations described in Section 4, average annual costs of asset management and fund administration are assumed to be 46 basis points.

${ }^{23}$ All currency returns are orthogonalized before being used as regressors.
} 


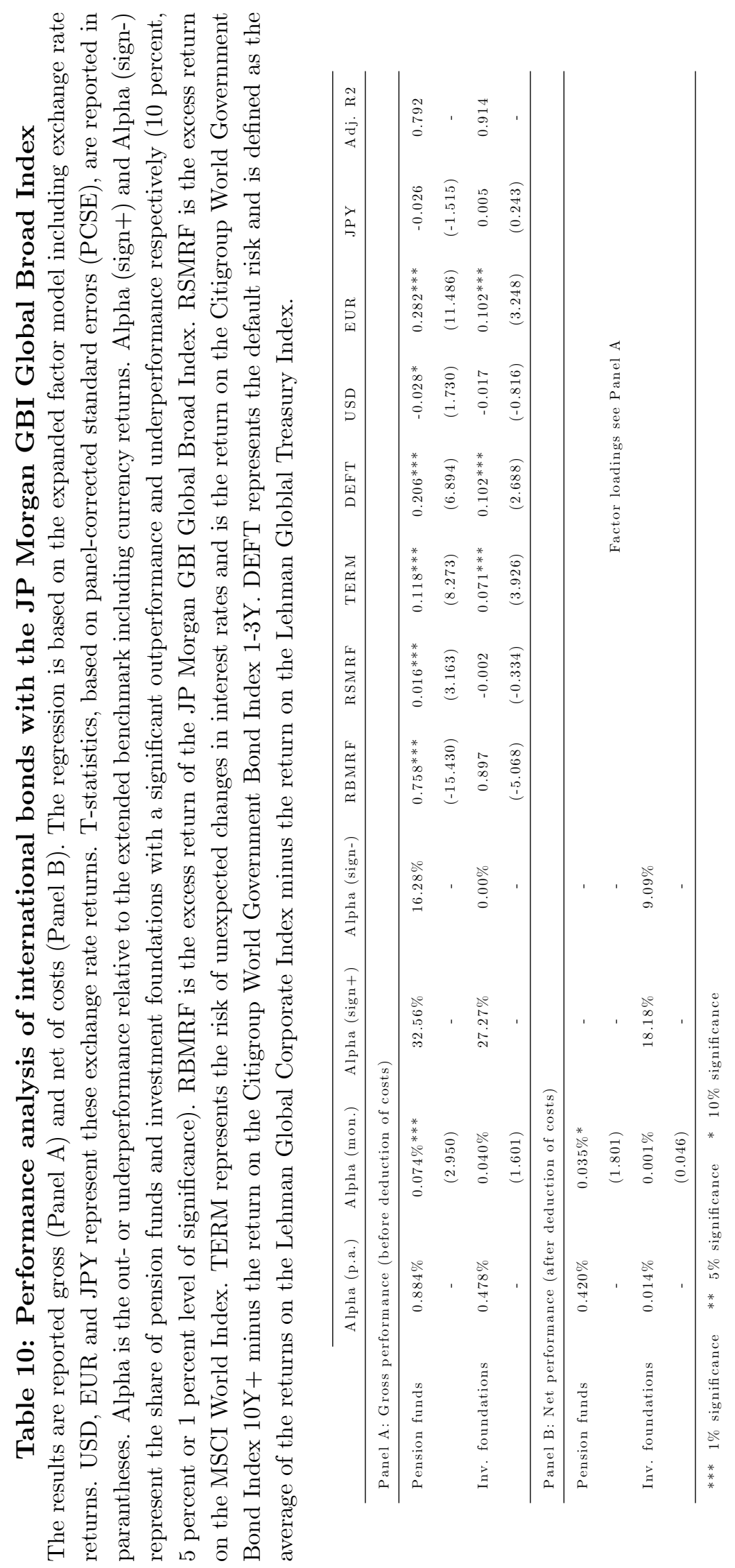


Bond Index would not be surprising for Swiss pension funds. Finally, the loading on $J P Y$ is statistically not significant indicating that the JPY has been neutrally weighted.

The loadings on $R B M R F, R S M R F$ and TERM do not change substantially compared to the benchmark model without currency factors. In contrast, the loading on DEFT is negative and statistically significant not only for investment foundations but now also for pension funds indicating a tendency towards government bonds. It seems that both pension funds and investment foundations hold more government bonds compared to the Lehman Global Aggregate Bond Index. Thus, we find some support for the initial hypothesis on the impact of the legal investment regulations on the investment strategies of pension funds and investment foundations.

Given this finding and the rather low EUR weighting of the Lehman Global Aggregate Bond Index, we test the robustness of our analysis by applying the JP Morgan GBI Global Broad Index. This index consists of government bonds only and has a currency allocation of about 20\% USD, $40 \%$ EUR, and $26 \%$ JPY as of mid-year 2006.

Table 10 reports the results of the panel regression based on the extended benchmark model with the JP Morgan GBI Global Broad Index. We find an annual (net) outperformance of $0.420 \%$ for pension funds significant at the $10 \%$ level. In contrast, the null hypothesis of neither out- or underperformance can still not be rejected for investment foundations.

The higher loadings on RBMRF seem to confirm the hypothesis that the JP Morgan GBI Global Broad Index is closer to the effective country and currency allocations of the bond portfolios in the sample. This reasoning is supported by the loadings on $U S D$ that are now only significant for pension funds (10\% level of significance). In contrast, the loadings on $E U R$ are still positive and significant at the $1 \%$ level both for pension funds and investment foundations indicating an over- or underweighting of the EUR relative to the four-factor benchmark model. An overweighting of the EUR would still not be surprising and might potentially explain the superior performance of pension funds. Finally, as expected, the loadings on DEFT turned positive, because the bond market factor is now represented by an index consisting of government bonds only.

We further investigate the robustness of the results for international bonds by applying a second government bond index, the Citigroup World Government Bond Index. We obtain similar results as for the benchmark model with the JP Morgan GBI Global Broad Index. This is an indication that the results of the performance analysis for investment foundations seem to be robust. The null hypothesis of neither our- or underperformance cannot be rejected for investment foundations. In contrast, the results of the performance analysis for pension funds depend on the benchmark model. The positive and statistically significant intercepts in two of three cases can be interpreted as an indication for superior skills of security selection and timing by pension funds. However, an outperformance due to a missing variable bias cannot be excluded, although the information content of all applied models is comparatively high. 


\subsection{Domestic equities}

The results of the panel regression for domestic equities based on Fama and French's three-factor model are shown in Table 11. From 1996 to 2006, the sample consists of 4,052 pension fund months and 1,382 investment foundation months. For investment foundations, we find no significant out- or underperformance. In contrast, for pension funds, we find a significant underperformance. Pension funds underperform the three-factor benchmark on average by $-0.588 \%$ per annum, as shown in Panel A. It must be pointed out that this underperformance is calculated before costs. If costs for asset management and fund administration are considered ${ }^{24}$, the average annual underperformance increases to $-1.155 \%$ and is significant at the $1 \%$ level (Panel B).

As observed already for bond holdings, pension funds exhibit less market risk than investment foundations. Although $R S M R F$ is statistically significantly different from 1 only for pension funds, it seems that both pension funds and investment foundations have remained rather close to the Swiss Performance Index. This hypothesis is supported by the rather high adjusted $R^{2}$. Thus, both pension funds and investment foundations seem to follow a rather passive investment strategy for domestic equities given the three-factor benchmark. Again, this is a surprising result especially for investment foundations because only 2 of the 13 investment foundations in the sample explicitly follow a passive investment strategy according to the official product descriptions.

Finally, Fama and French's three-factor model can be interpreted as a performance attribution model since the loadings on the factor-mimicking portfolios $S M B$ and $H M L$ contain information about two fundamental investment decisions: large versus small market capitalization and value versus growth stocks. Small caps tend to have a positive loading on $S M B$, while large caps tend to have a negative loading. Similarly, a positive loading on $H M L$ indicates a value style and a negative loading indicates a growth tilt. As shown in Table 11, pension funds seem to prefer small caps as well as growth stocks with low book-to-market equity. The factor loadings on $S M B$ are significant at the $5 \%$ level, the factor loadings on $H M L$ at the $1 \%$ level. In contrast, investment foundations seem to prefer large caps and value stocks. Again, the factor loadings are highly significant. Thus, the effect of the statutory investment regulations is again not as expected for pension funds.

Given the high explanation content of the applied model and the fact that we find no significant outperformance both for pension funds and investment foundations, the missing variable bias should also be of limited importance for domestic equities. The issue of time-varying factor exposures is addressed in Section 7.2.

\subsection{International equities}

The performance analysis of international equities is based on a sample of 3,640 monthly returns of pension funds and 1,162 monthly returns of investment foundations from 1996 to 2006. Table 12 reports the results of the panel regression based on Fama and French's three-factor model. The negative, but statistically not significant intercepts in Panel A indicate no superior performance of pension funds and investment foundations. However, when looking at individual results, we find no

\footnotetext{
${ }^{24}$ Based on the estimate for investment foundations described in Section 4, average annual costs of asset management and fund administration are assumed to be 57 basis points.
} 


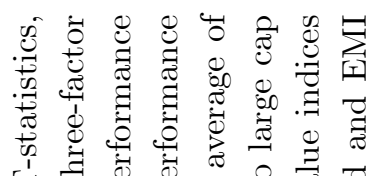

H

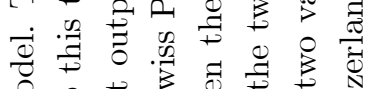

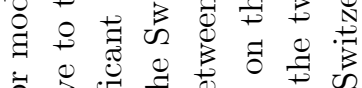

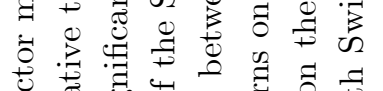

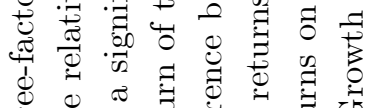

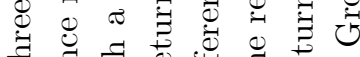

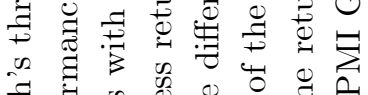

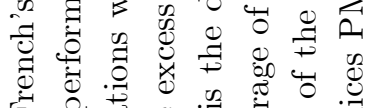

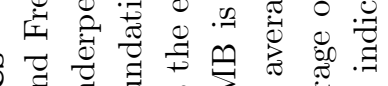

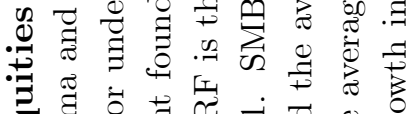

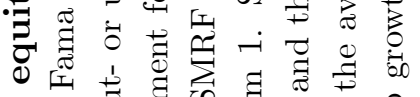

.

⿹

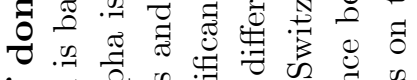

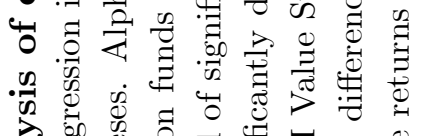

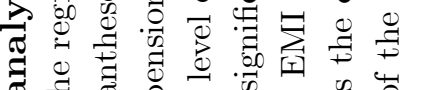

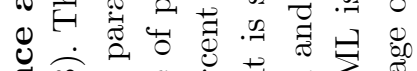

สิ

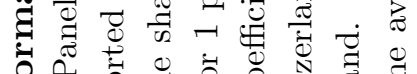

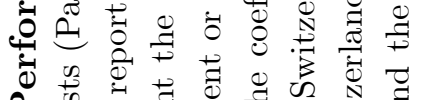

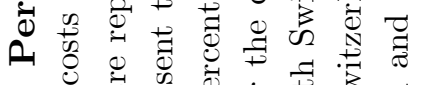

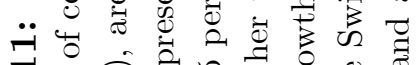

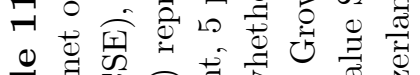

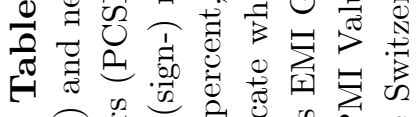

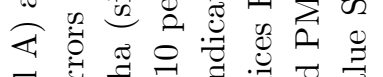
它

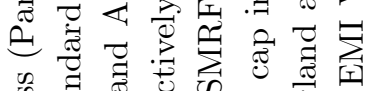

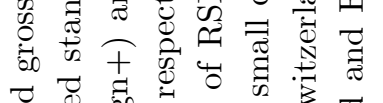

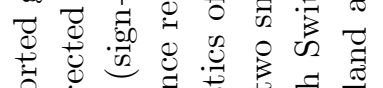

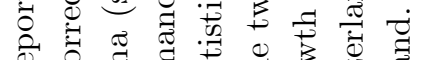
记

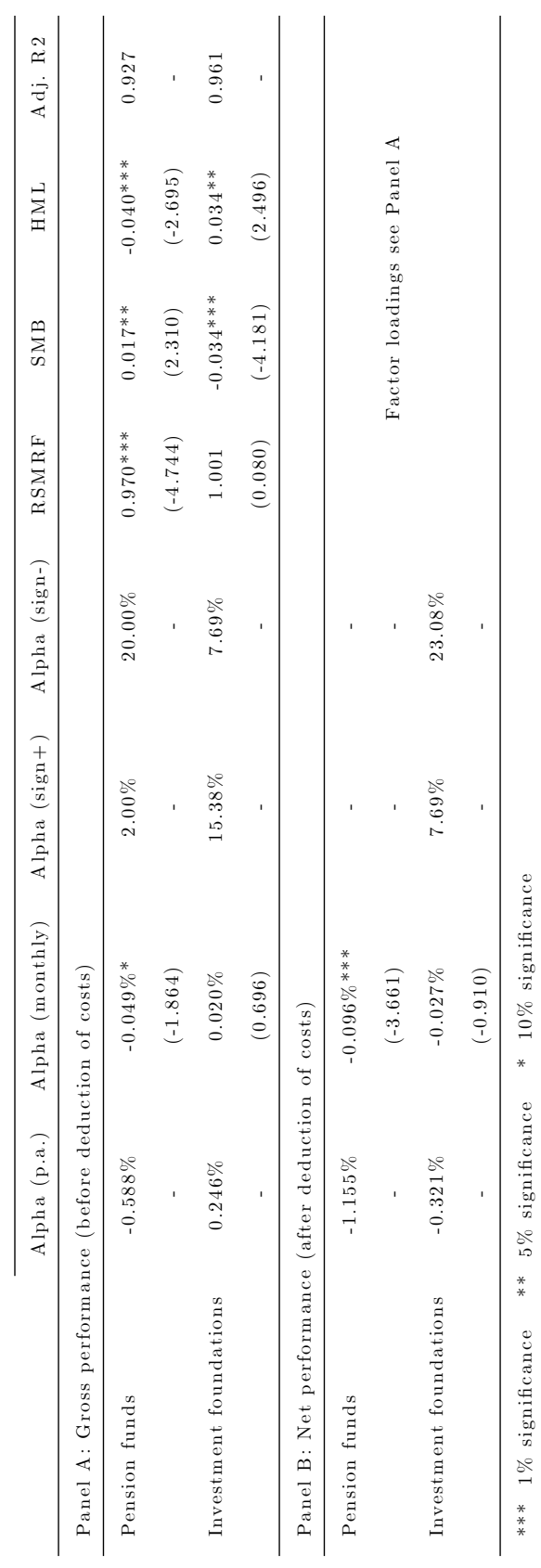

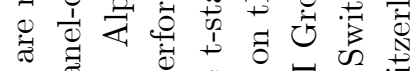

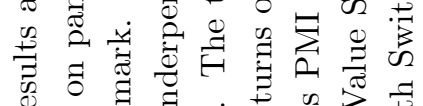

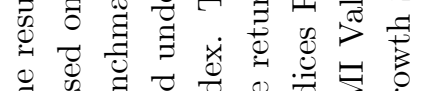

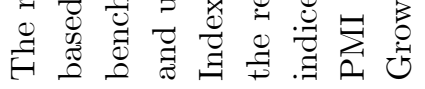


outperformers in the sample. Furthermore, net of costs, we find a significant average annual underperformance of $-1.040 \%$ for investment foundations. For pension funds, we find a significant underperformance after deduction of asset management and administration costs ${ }^{25}$ of $-1.609 \%$, significant at the $1 \%$ level.

As indicated by the $R S M R F$ coefficients, both pension funds and investment foundations exhibit significantly less market risk than the MSCI World Index. However, looking at the adjusted $R^{2}$ of 0.927 for pension funds and 0.952 for investment foundations, it seems that pension funds and investment foundations have remained quite close to the four-factor benchmark. In the light of only one investment foundation investing passively according to the official product descriptions, this is a similarly surprising finding as for the other asset classes.

According to the loadings on $S M B$ and $H M L$ in Table 12, both pension funds and investment foundations seem to prefer small caps and growth stocks. For pension funds and investment foundations, the factor loadings are both significant at the $1 \%$ level. Thus, pension funds seem to follow the same investment style for international equities as for domestic equities, whereas investment foundations seem to follow different investment strategies for domestic and international equities. Again, the effect of the statutory investment regulations is not as expected.

As before, we extend our benchmark model with exchange rate returns to account for country and currency allocations different from the three-factor benchmark. Significant loadings on the currency factors can indicate over- or underweighting of specific currencies relative to the three-factor benchmark.

Table 13 reports the results of the panel regression for international equities based on the extended benchmark model. We find a significant underperformance of pension funds even before costs of asset management and administration are considered. The average annual net underperformance of pension funds and investment foundations is confirmed by the extended benchmark model. The currency factors do not reveal much additional information. None of the currency factors is significant and the adjusted $R^{2}$ is almost the same compared to the three-factor model. Thus, it seems that the USD, the EUR, the JPY and the GBP were neutrally weighted relative to the benchmark model.

Given the high explanatory power of the model applied and the fact that we find a significant underperformance both for pension funds and investment foundations, the missing variable bias should be of limited importance for international equities. The issue of time-varying factor exposures is addressed in the following section.

\section{$7 \quad$ Persistence analysis}

In this section, we verify whether there is persistence in the performance and in the investment strategies of Swiss pension funds and investment foundations.

\subsection{Persistence of investment performance}

Although we find overall no significantly superior performance of pension funds and investment foundations in three out of four asset classes, there are outperformers in

\footnotetext{
${ }^{25}$ Based on the estimate for investment foundations described in Section 4, average annual costs of asset management and fund administration are assumed to be 81 basis points (excluding AAA).
} 


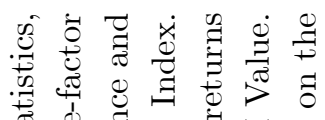

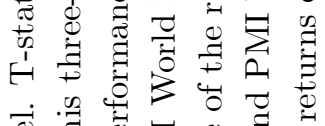

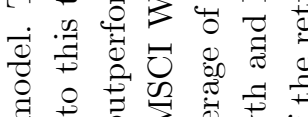

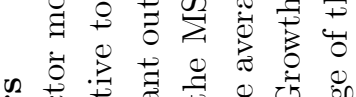

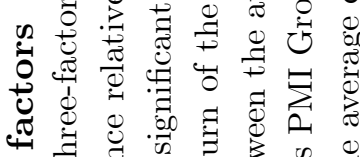

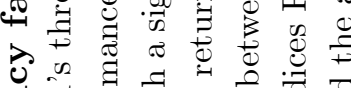

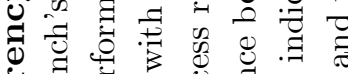

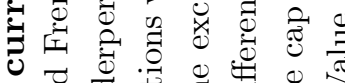

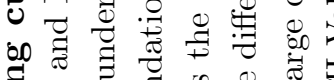

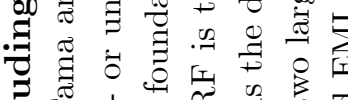

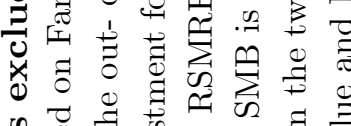

की

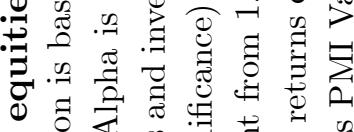

ส

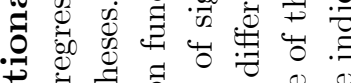

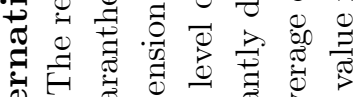

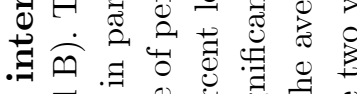

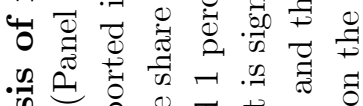

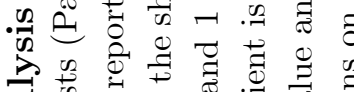

สే

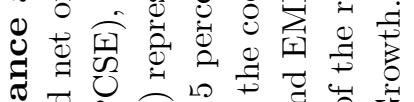

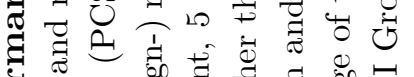

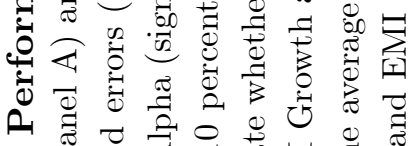

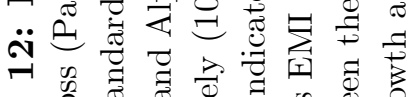

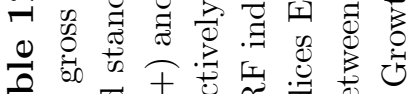

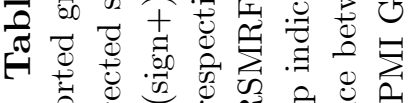

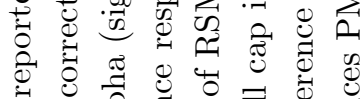

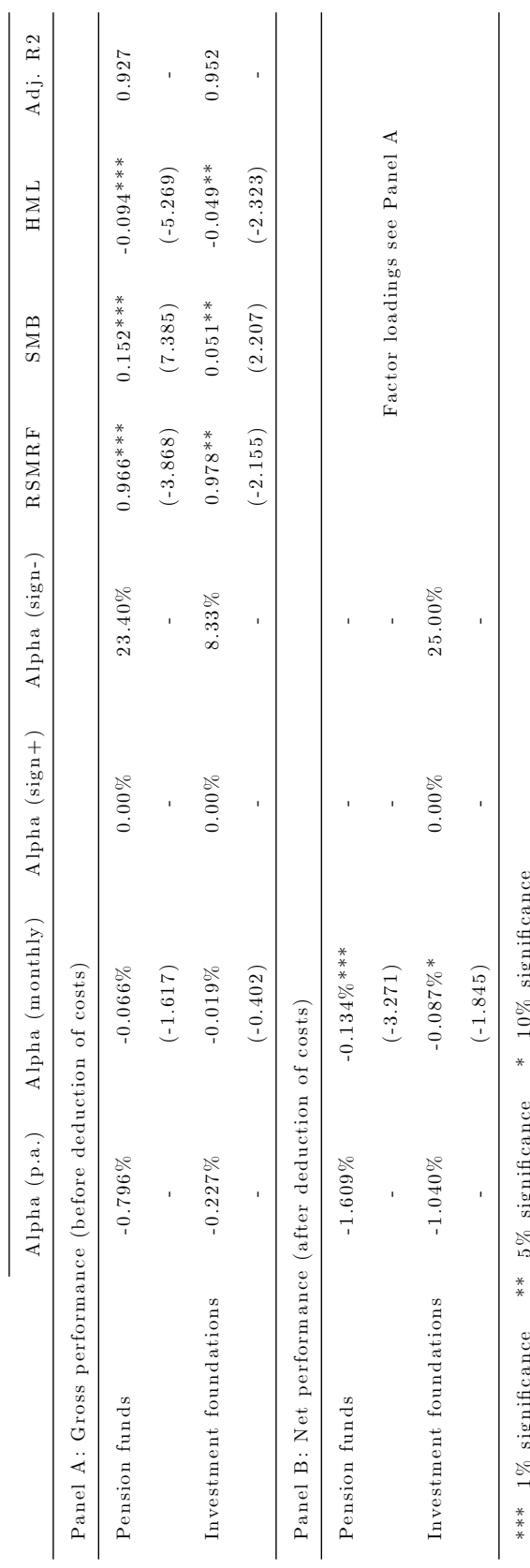

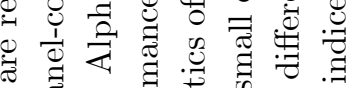

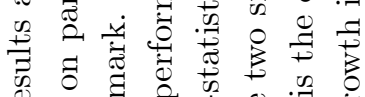

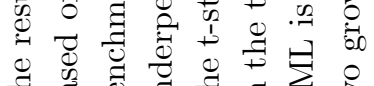

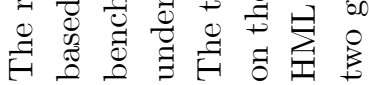




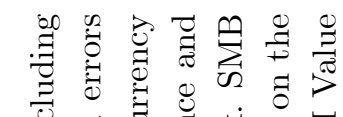

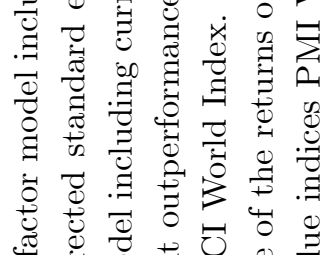

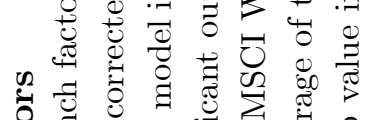

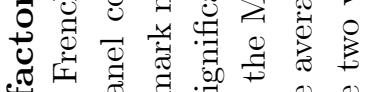

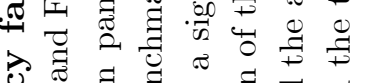

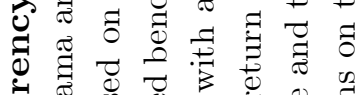

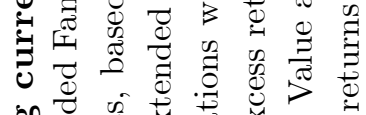

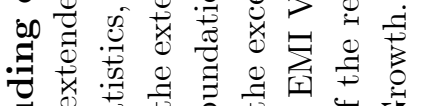

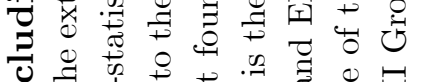

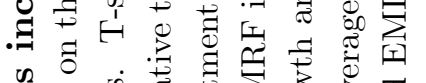

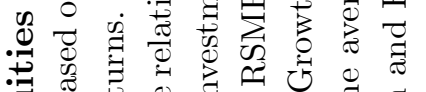

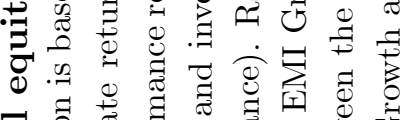

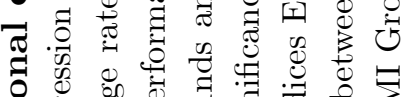

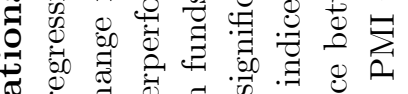

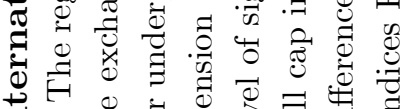

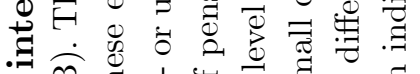

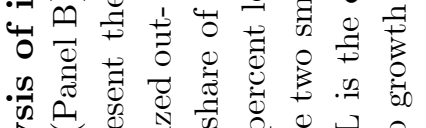

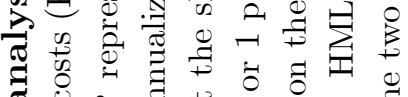

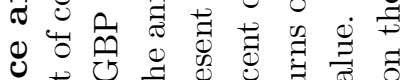

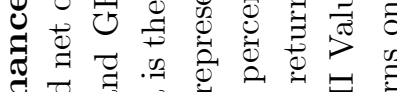

ป च

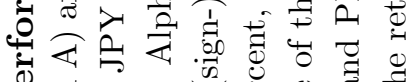

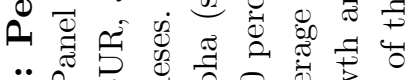

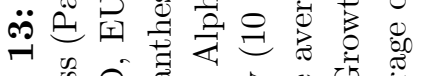

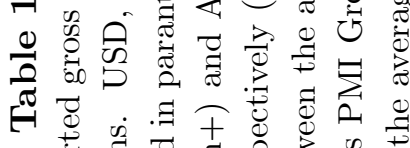

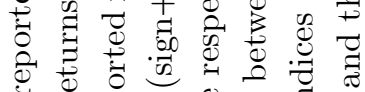

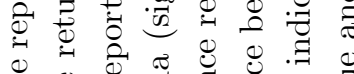

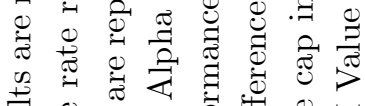

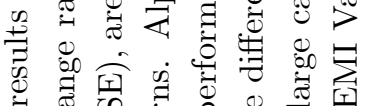

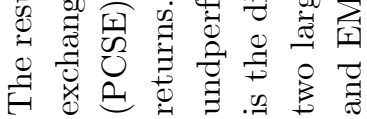

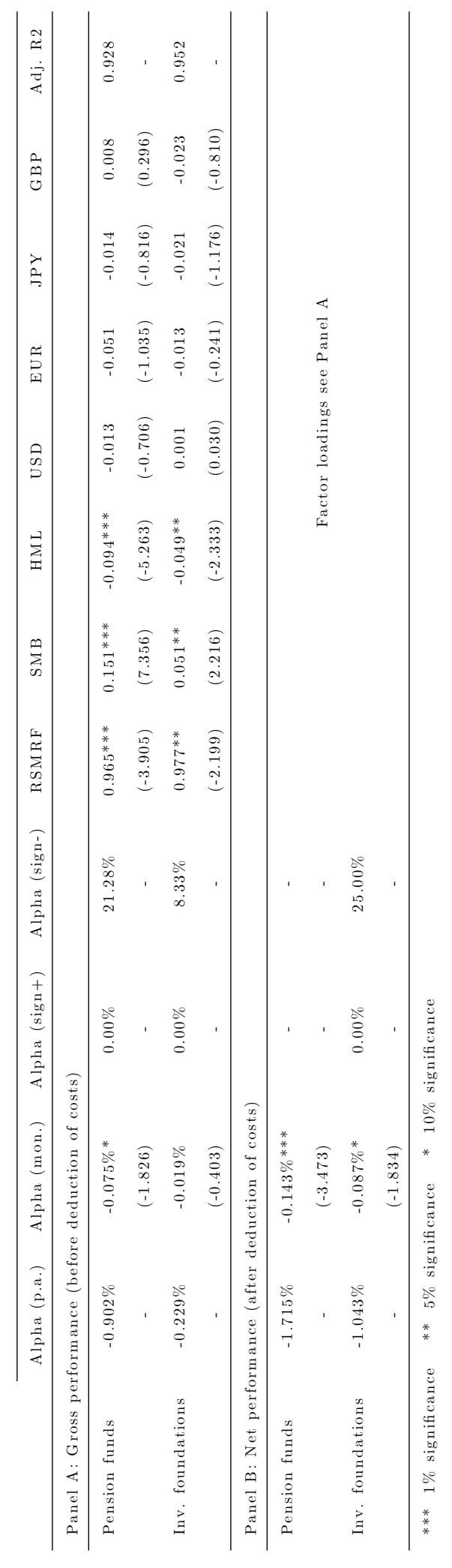


each asset class except for international equities. An obvious question to ask is now whether pension funds and investment foundations that have performed well in prior periods can repeat this outperformance in subsequent periods. Because we focus on individual asset classes in our analysis, this is synonymous to the question whether pension fund trustees are able to identify (internal and external) asset managers that consistently outperform the benchmark on a risk-adjusted basis.

Previous research on persistence in the performance of pension funds focuses on U.K. and the U.S.. Beebower And Bergstrom (1977) were among the first to analyze the persistence in the performance of pension funds. They find persistence in the performance of U.S. pension funds' equity portfolios. Brown, DrAPER, AND McKenzie (1997) and Blake, Lehmann, and Timmermann (1997) confirm these findings for U.K. pension funds. Based on a sample of pension funds that retained a single asset manager across the entire period of investigation, they find persistence in the performance of pension funds' equity holdings, albeit only on a limited scale. TONKS (2005) argues that focusing only on pension funds with the same single manager may underestimate the true degree of persistence because the survivorship criteria for asset managers is likely to depend on the past investment performance. Using a data sample with less survivorship bias, he finds strong evidence of persistence in the performance of fund managers at the 1-year time horizon but weaker evidence over longer horizons. Little research has been done on persistence in the performance of Swiss pension funds. Ammann, HaEller, AND VON Wyss (2002) investigate the persistence in the performance of six Swiss investment foundations. In contrast to the research on U.K. and U.S. pension funds, they find no evidence of persistence in the performance of Swiss investment foundations.

We follow CARHART (1997) and sort pension funds and investment foundations on January 1 each year from 1996 to $2006^{26}$ into equal-weight sextile portfolios based on their alphas estimated over the prior three years ${ }^{27}$. A minimum of 24 observations is required for this estimation. Pension funds and investment foundations with the highest alpha are contained in portfolio 1 for the subsequent 1-year period. In contrast, pension funds and investment foundations with the lowest alpha are contained in portfolio 6 for the subsequent 1-year period. To demonstrate persistence in the performance, portfolio 1 must outperform at least portfolio 6 .

Table 14 reports the results of the persistence analysis for pension funds' and investment foundations' bond portfolios. As shown in Panel A, for domestic bonds, the top sextile portfolio outperforms the other portfolios by only 2 to 3 basis points per month, a difference of far less than two standard errors. Thus, we find no significant persistence in the performance of domestic bonds. Panel B shows, for international bond portfolio 1 , an alpha that is only about 1 basis points per month. Thus, the monthly alphas of the other portfolios are covered by the $95 \%$ confidence interval of portfolio 1's alpha. There is no evidence of persistence in the performance of pension funds' and investment foundations' international bond holdings.

The results of the performance analysis for domestic (Panel A) and international equities (Panel B) are displayed in Table 15. For domestic equities, we find an

\footnotetext{
${ }^{26}$ The persistence analysis for international bonds is based on a shortened reference period from 2001 to 2006.

${ }^{27}$ We apply the benchmark models described in Section 5. For international bonds and international equities we use the extended benchmark models with exchange rate factors.
} 


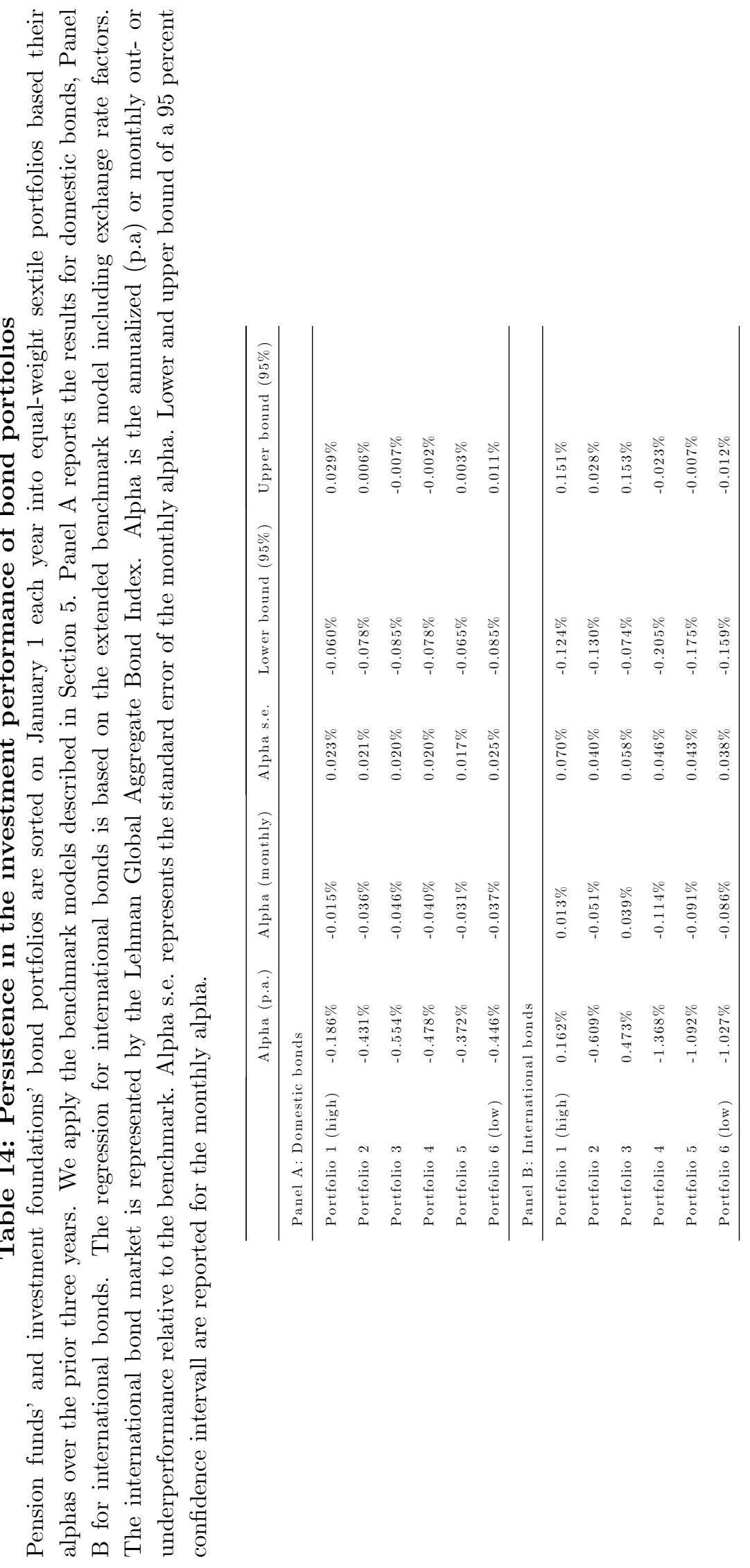




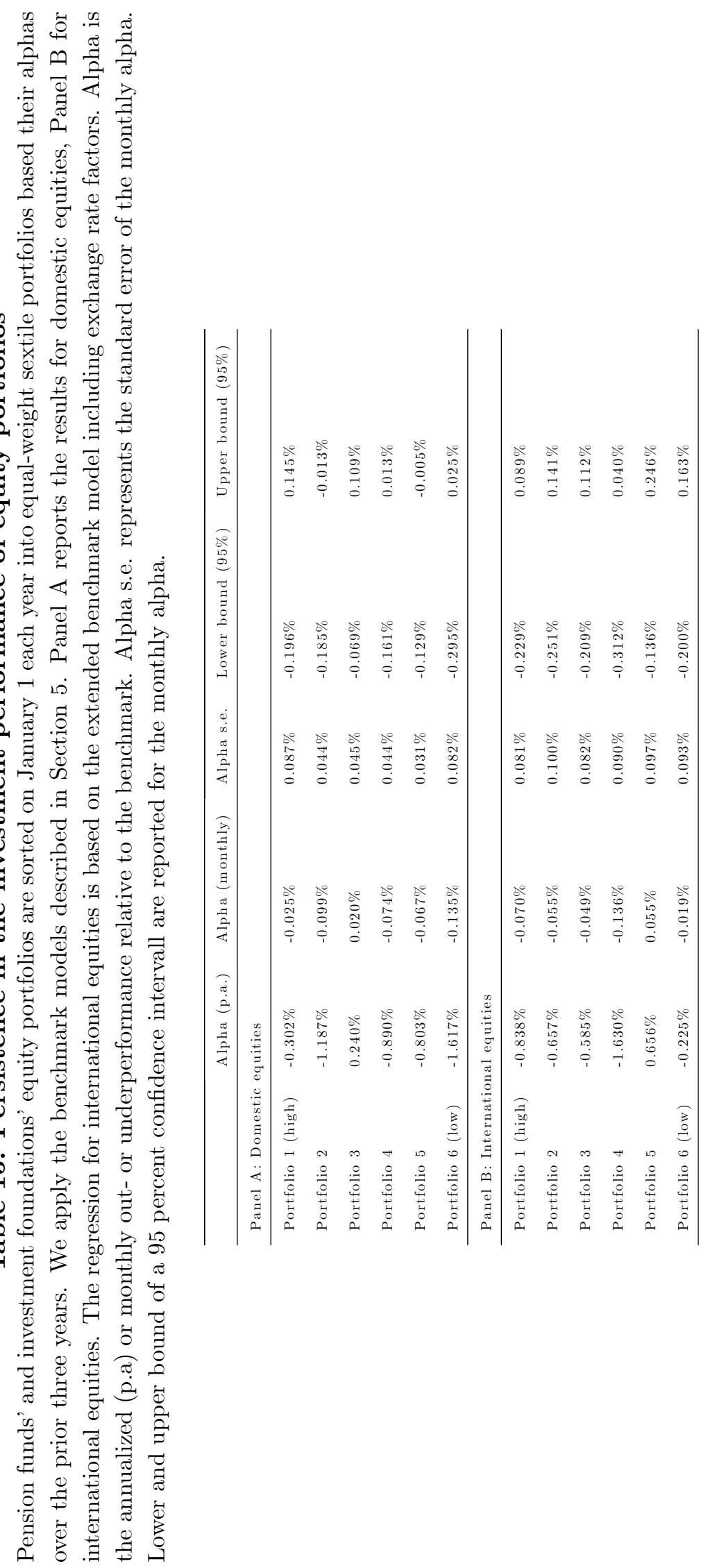


outperformance of portfolio 1 relative to the bottom sextile portfolio. However, the monthly performance difference of $0.11 \%$ is statistically not significant. Similarly, the top sextile international equity portfolio even shows an alpha that is below the bottom sextile portfolio. Therefore, we can conclude that there is no evidence of persistence in the performance of pension funds' and investment foundations' equity holdings.

Thus, past performance seems to be a poor way of identifying outperforming pension funds. Pension fund trustees do not seem to be able to select (internal and external) asset managers that consistently outperform the benchmark. On the one hand, it could be argued that pension fund trustees should improve their (asset) manager selection process. A clear and transparent selection process implies among other things a detailed catalogue of criteria for the evaluation of asset managers. On the other hand, it remains an open question whether constantly outperforming asset managers are identifiable in advance. Furthermore, manager selection is just one of numerous aspects of pension fund governance.

\subsection{Persistence of investment strategies}

We used the performance measurement models in the previous section to draw some conclusions regarding the investment strategies of the pension funds and investment foundations in the sample. Significant factor loadings reveal information on the average investment strategy over the entire period of investigation. However, investment strategies might vary over time and, as a result, the regression intercepts might be biased. Therefore, we verify in this section the persistence of investment strategies. For this purpose we split the initial period of investigation in two sub-periods of equal length and apply the same multi-factor models as in Section 6 .

For domestic bonds we show that both pension funds and investment foundations seem to be positioned at the long end of the yield curve and that investment foundations show a tendency towards government bonds over the entire period of investigation. Table 16 shows the results of the performance analysis for the two sub-periods from January 1996 to March 2001 and from April 2001 to 2006. Overall, we find no fundamental shift of the investment strategies. However, for investment foundations we find the tendency towards government bonds only in the first subperiod. In contrast, in the second sub-period there seems to be no clear tendency towards government or corporate bonds. Pension funds, in turn, seem to be positioned at the long end of the yield curve only in the second sub-period. In the first sub-period they have a tilt towards government bonds, whereas we find no significant tendency over the entire period of investigation.

According to our performance analysis of international bonds, both pension funds and investment foundations are on average positioned at the long end of the yield curve and have a tilt towards government bonds. For investment foundations, we find indications for this investment strategy in both sub-periods, as shown in Table 17. Pension funds also show a tendency towards long-term maturities in both subperiods. However, a significant tilt towards government bonds is only found in the second sub-period.

For domestic equities, pension funds and investment foundations seem to follow different investment strategies. Over the entire period of investigation pension funds seem to prefer small caps as well as growth stocks, whereas investment foundations 


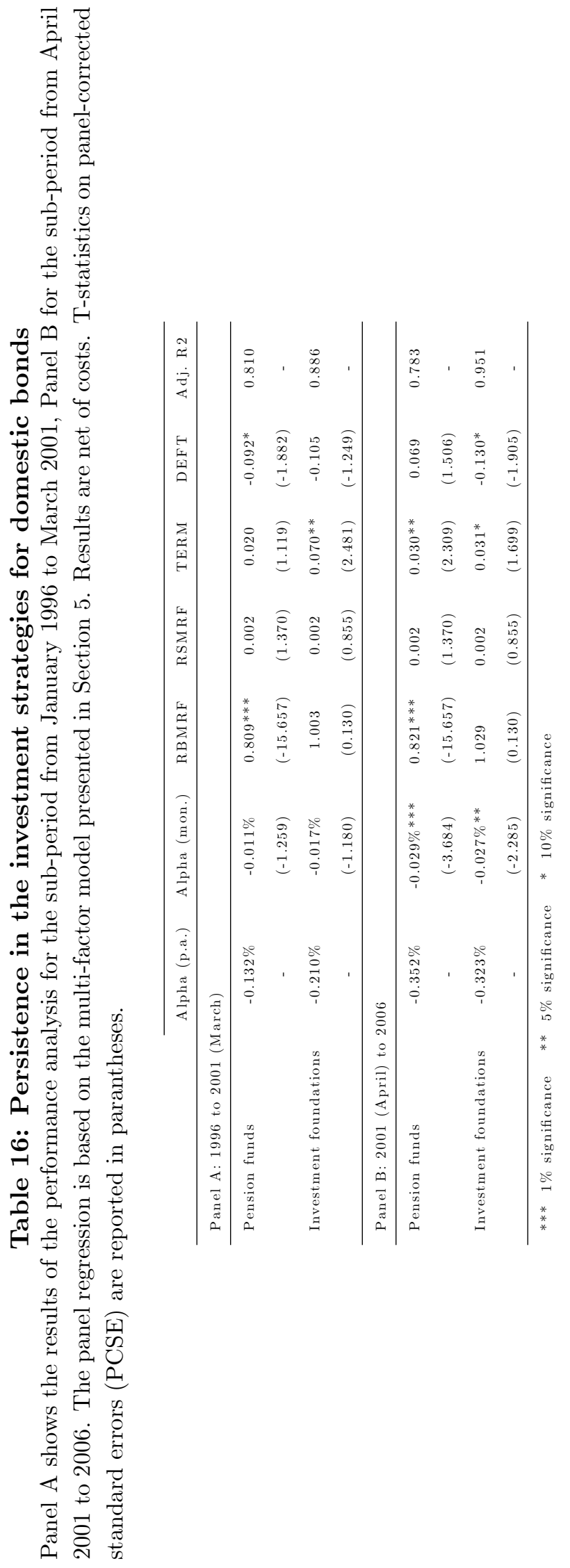




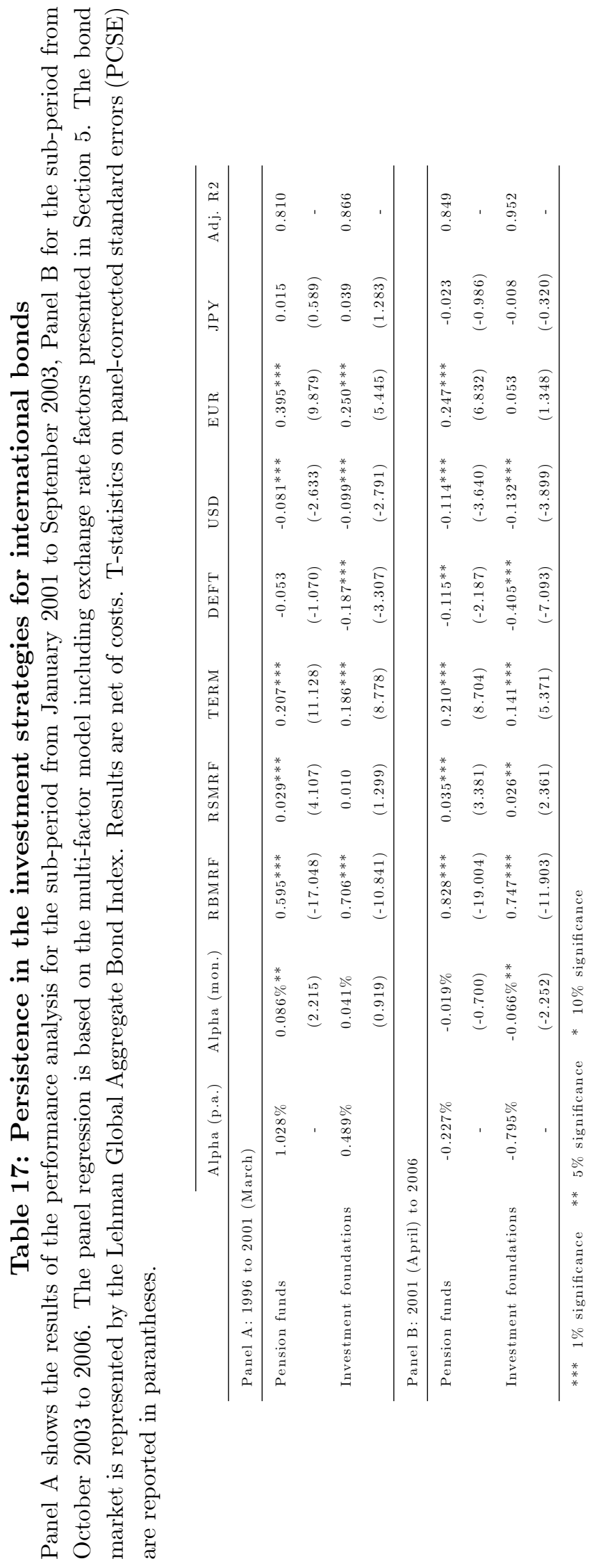




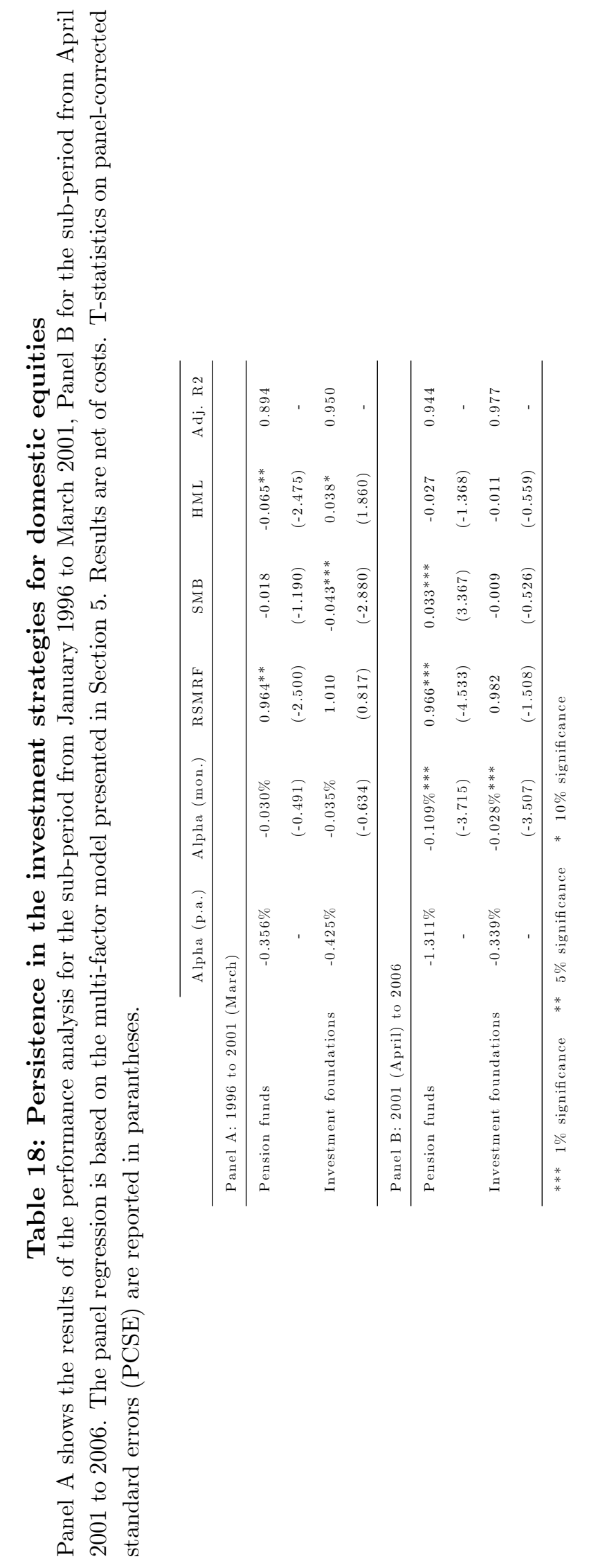




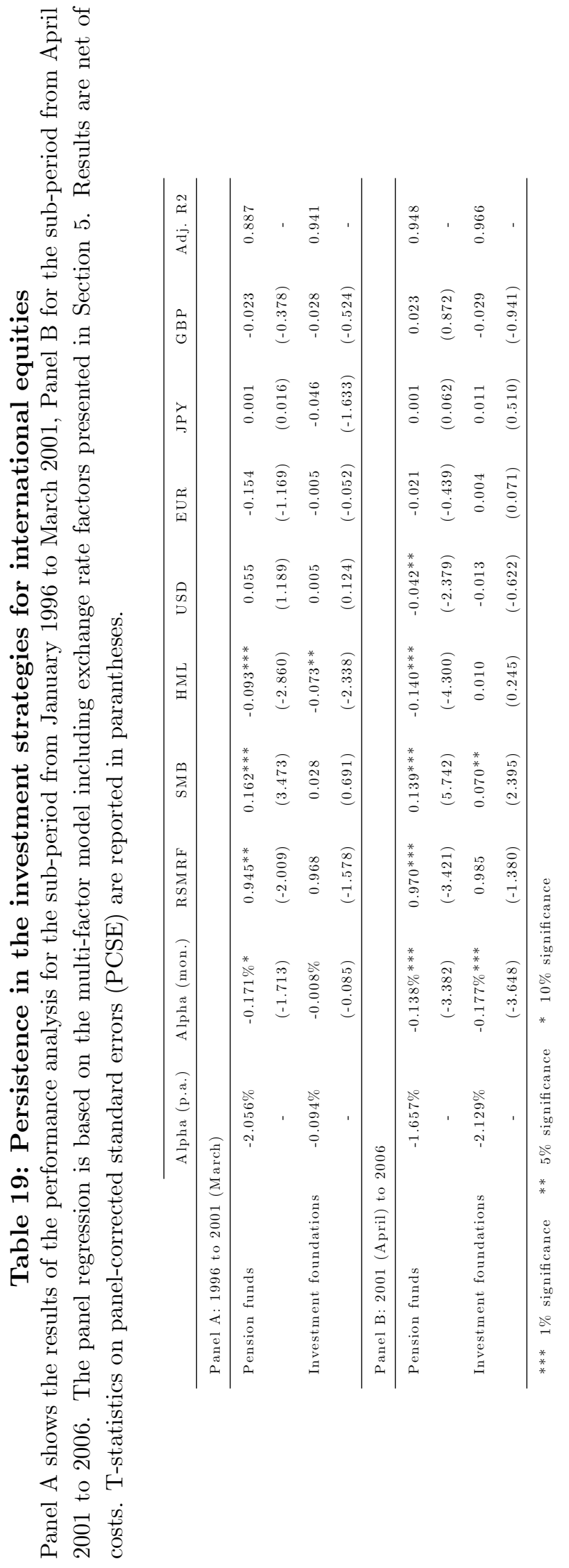


show a tendency towards large caps and value stocks. Again, we find no fundamental strategy shift between the two sub-periods. However, we find a significant occurrence only in one of the two sub-periods, as shown in Table 18.

Finally, Table 19 reports the results of the persistence analysis for international equities. Over the period from 1996 to 2006 both pension funds and investment foundations follow the same investment strategy in this asset class. As over the entire period of investigation, pension funds prefer small caps and growth stocks in both sub-periods. Investment foundations, in contrast, show a significant tendency towards small caps and growth stocks only in one of the two sub-periods.

Summarizing, we find no indications for fundamental strategy shifts. However, pension funds and investment foundations seem to show a clear positioning only for a limited period of time. In the remaining time they do not take an offsetting but a neutral position. Since we find no fundamental strategy variations, our empirical results should not be biased due to time-varying factor exposures.

\section{Conclusion}

In this article we investigate the performance of domestic and international bond and equity portfolios of Swiss pension funds and investment foundations. For Swiss pension funds, we find indications for superior skills of security selection and timing only in international bond management. On the other hand, the performance of the other asset classes lags behind the risk-adjusted benchmark returns. The underperformance of equities is significant even before deduction of any costs for asset management and fund administration. Thus, our investigations confirm the findings of previous research on the performance of U.K. and U.S. pension funds.

Swiss pension funds seem to follow a more active investment approach than investment foundations. However, the contribution of the more active asset management of pension funds seems to be negative. Except for international bonds, the risk-adjusted performance of the more passively positioned investment foundations tends to be higher than the performance of pension funds. Nevertheless, we find a significant underperformance net of costs also for investment foundations' domestic bonds and international equities, whereas for international bonds and domestic equities the null hypothesis of neither significant out- or underperformance cannot be rejected.

We find no evidence that the risk-adjusted performance of pension funds' and investment foundations' international asset classes is lower than the performance of domestic asset classes. This contradicts the findings of previous research.

The interpretation of the factor models as performance attribution models gives some indication on the investment strategies of pension funds and investment foundations. Pension funds seem to follow the same investment strategy for domestic and international equities. Perhaps not as expected, they seem to prefer small caps and growth stocks. In contrast, investment foundations seem to follow different investment strategies for domestic and international equities. For domestic equities, they prefer large caps and value stocks. For international stocks, they follow the same strategy as pension funds. We find a growth tilt and a tendency towards small capitalization stocks.

Moreover, we find no empirical evidence that legal investment regulations affect 
the investment strategies of Swiss pension funds within the individual asset classes. The underperformance in three out of four asset classes cannot be attributed to excessive self-constraints by pension funds. It seems that self regulation guided by a few general legal principles is sufficient. Additional legal regulations governing the investments of pension funds within individual asset classes does not seem to be required $^{28}$. However, this does not imply that investment regulations do not affect the performance of pension funds at all. The quantitative limitations, even if exemptions have become the rule, influence the asset allocation of Swiss pension funds to a great extent. The vast majority of pension funds in Switzerland structure their assets in domestic bonds, international bonds, domestic equities and international equities. This partially explains the strong home bias of Swiss pension funds.

Although we find only little evidence for superior performance, there are outperforming pension funds and investment foundations in each of the four asset classes. However, we find no evidence of persistence in the performance of pension funds and investment foundations. Thus, pension fund trustees seem not to be able to select asset managers that consistently outperform the benchmark. This contradicts the findings of previous research on the persistence of U.K. and U.S. pension funds. Although we find no evidence of persistence, Swiss pension funds do not seem to do worse than U.K. or U.S. pension funds.

Concluding, we do not expect legal investment regulations to be a lever for improvement of pension funds' investment performance. The current regulations leave sufficient flexibility for pension funds and we find that pension fund trustees make use of this flexibility. In contrast, the contribution of active asset management should be more critically reviewed. On the one hand, active asset management fees are only justified for effective active asset management. In this regard, we see improvement potential both for investment foundations and pension funds. Most important, the performance net of costs needs to be thoroughly assessed and consequences taken, if necessary, on a regular basis.

\footnotetext{
${ }^{28}$ ZINGG, LANG, AND WYTtenBACH (2007) provide another example of successful self-regulation in Switzerland.
} 


\section{References}

Ambachtsheer, K. P., R. Capelle, and T. Scheibelhut (1998): "Improving Pension Fund Performance," Financial Analysts Journal, 54(6), 15-21.

Ammann, M., C. Haeller, and R. von Wyss (2002): "Performance Schweizerischer Anlagestiftungen," Financial Markets and Portfolio Management, 16(4), $446-466$.

Ammann, M., and M. Steiner (2008): "Risk Factors for the Swiss Stock Market," Swiss Journal of Economics and Statistics, 144(1), 1-35.

Beck, N., And J. N. Katz (1995): "What to do (and not to do) with Time-Series Cross-Section Data," American Political Science Review, 89(3), 634-647.

Beebower, G. L., and G. L. Bergstrom (1977): "A Performance Analysis of Pension and Profit-Sharing Portfolios: 1966-1975," Financial Analysts Journal, 33(3), 31-42.

Blake, C. R., E. J. Elton, and M. J. Gruber (1993): "The Performance of Bond Mutual Funds," Journal of Business, 66(3), 371-403.

Blake, D., B. Lehmann, and A. Timmermann (1997): "Performance Measurement using Multi-Asset Portfolio Data: A Study of U.K. Pension Funds," Discussion paper, Pensions Institute, Birkbeck College.

Blake, D., B. N. Lehmann, and A. Timmermann (1999): "Asset Allocation Dynamics and Pension Fund Performance," Journal of Business, 72(4), 429-461.

Blake, D., and A. Timmermann (2005): "Returns from Active Management in International Equity Markets: Evidence from a Panel of U.K. Pension Funds," Journal of Asset Management, 6(1), 5-20.

Brinson, G. P., L. R. Hood, and G. L. Beebower (1986): "Determinants of Portfolio Performance," Financial Analysts Journal, 42(4), 39-44.

Brinson, G. P., B. D. Singer, and G. L. Beebower (1991): "Determinants of Portfolio Performance II: An Update," Financial Analysts Journal, 47(3), 40-48.

Brown, G., P. Draper, and E. McKenzie (1997): "Consistency of U.K. Pension Fund Investment Performance," Journal of Business Finance and Accounting, $24(2), 155-078$.

Carhart, M. M. (1997): "On Persistence in Mutual Fund Performance," Journal of Finance, 52(1), 57-82.

Coggin, D. T., F. J. Fabozzi, and S. Rahman (1993): "The Investment Performance of U.S. Equity Pension Fund Managers: An Empirical Investigation," Journal of Finance, 48(3), 1039-1055.

Cumby, R. E., And J. D. Glen (1990): "Evaluating the Performance of International Mutual Funds," Journal of Finance, 45(2), 497-521. 
Detzler, M. L. (1999): "The Performance of Global Mutual Funds," Journal of Banking and Finance, 23, 1195-1217.

Eidgenossenschaft (2006): "Szenarien zur Bevölkerungsentwicklung der Schweiz 2005-2050," Technical report, Federal Statistical Office.

Elton, E. J., M. J. Gruber, and C. R. Blake (1995): "Fundamental Economic Variables, Expected Returns, and Bond Fund Performance," Journal of Finance, 50(4), 1229-1256.

Fama, E. F., and K. R. French (1993): "Common Risk Factors in the Returns on Stocks and Bonds," Journal of Financial Economics, 33(1), 3-56.

Ippolito, R. A., And J. A. Turner (1987): "Turnover, Fees and Pension Plan Performance," Financial Analysts Journal, 43(6), 16-26.

Lakonishok, J., A. Shleifer, R. W. Vishny, O. Hart, and G. L. Perry (1992): "The Structure and Performance of the Money Management Industry," Brooking Papers on Economic Activity, 1992, 339-391.

Lusenti, G. (2007): "Swiss Institutional Survey," Study report, Lusenti Partners, Zurich.

Thomas, A., And I. Tonks (2001): "Equity Performance of Segregated Pension Funds in the U.K.," Journal of Asset Management, 1(4), 321-343.

Timmermann, A., and D. Blake (2005): "International Asset Allocation with Time-Varying Investment Opportunities," Journal of Business, 78(1), 71-98.

Tonks, I. (2005): "Performance Persistence of Pension-Fund Managers," Journal of Business, 78(5), 1917-1942.

ZingG, A., S. Lang, and D. Wyttenbach (2007): "Insider Trading in the Swiss Stock Market," Swiss Journal of Economics and Statistics, 143(3), 331-362. 